


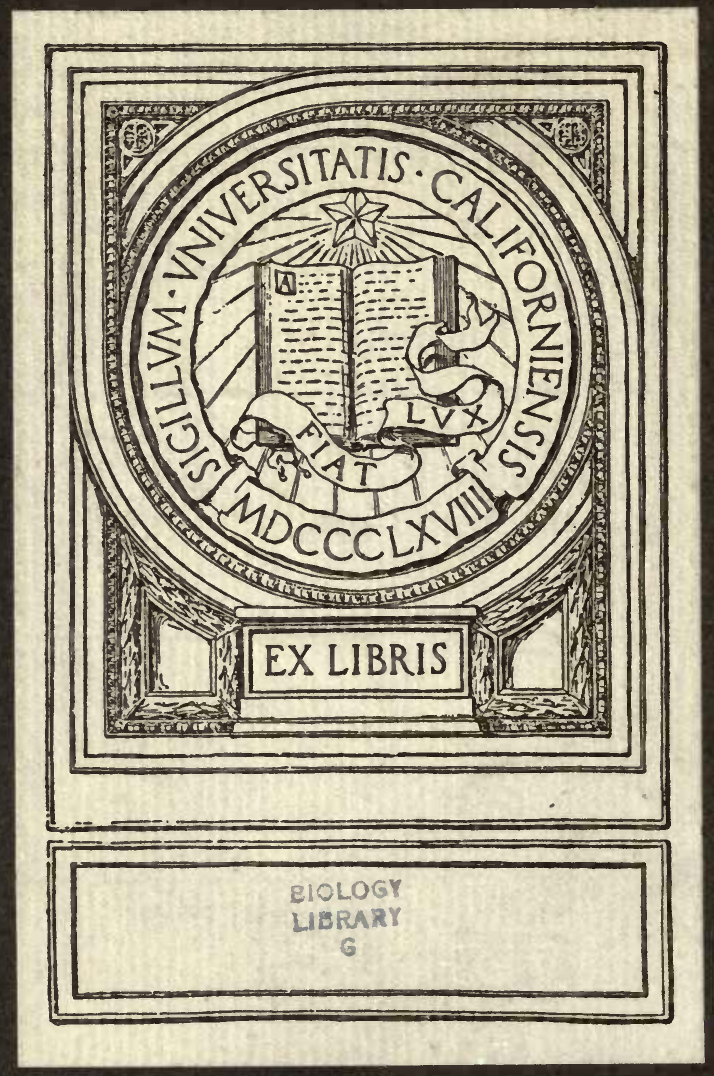




\section{$\therefore \therefore$ ㅇ}

\section{THE CONGENITAL SEXUAL BEHAVIOR OF THE YOUNG MALE ALBINO RAT}

BI

CALVIN P. STONE, A.B., A.M.

Submitted in Partial Fulfillment of the Requirements for the Degree of Doctor of Philosophy in the Department of

Psychology, University of Minnesota, June, 1921 



\title{
THE CONGENITAL SEXUAL BEHAVIOR OF THE YOUNG MALE ALBINO RAT
}

\author{
CALVIN P. STONE 1 \\ University of Minnesota
}

\section{INTRODUCTION}

\section{Purpose of investigation}

The general use of experimental technique in the study of congenital behavior of lower and higher animals reflects a gradually changing trend of psychological interest in this subject. Interest is shifting from problems centered in the determination of significant relationships between conscious and organic processes to those defining units of response and analyzing the stimuli by which they are activated. As yet, however, in the field of animal psychology, investigations of congenital behavior have not been sufficiently intensive to give a complete account of either the overt patterns of activity or the activating stimuli. They have furthered an understanding of limited aspects of particular responses, given valuable suggestions along lines of methodology, and copiously illustrated the erroneous nature of many of the older conceptions concerning native behavior; but, in general, the scope of these accounts is too limited to place our knowledge of the subject as a whole on a fundamental working basis. For this reason there is need, at the present time, of comprehensive studies of fundamental types of native behavior. Intensive studies will yield data that may be used as guides in the reorganization and expansion of current views of these activities.

For the advancement of the science of animal behavior, there is need of intensive genetic studies of complex patterns of native behavior to ascertain the life histories of both the constituent elements and the patterns as wholes. With respect to the

\footnotetext{
${ }^{1}$ I wish hereby to acknowledge my indebtedness to Dr. K. S. Lashley at whose
} suggestion and under whose direction this experiment was conducted. 
nature of activating stimuli our knowledge is very incomplete. For the most part investigators have dealt with the external stimuli alone. They have overlooked the internal factors. Now, to really understand the activation of native patterns of response, it is necessary to take the latter into account as well; for the external stimuli merely discharge the elaborate and complex neuromuscular and glandular mechanisms pre-organized by the action of potent internal factors operating within the organism. A preliminary survey of the internal factors operating would seem to indicate that at least two distinct types can be recognized. There is a group which underlies the development and integration of the neuro-muscular and glandular mechanisms, and another that serves to keep the mechanisms in a state of readiness for response to particular patterns of external stimulation.

The field of congenital sexual activity offers a favorable opportunity for an intensive and comprehensive study of a type of behavior both typical and universal. It is a type which may be satisfactorily studied in the ordinary laboratory animals; and it should yield data of both theoretical and practical importance for many general phases of congenital activity. On this account congenital sexual behavior was subjected to experimental study in this investigation. The study is concerned primarily with the copulatory act of the young male albino rat.

On the whole the rat is a very satisfactory animal for observation in a study of sexual behavior. It thrives well in confinement, becomes sexually mature in a relatively short time (sixty to ninety days), and displays its sexual behavior, under appropriate stimulation, throughout the entire year. The copulatory act of the animal is one that may be studied from many aspects. Its appearance in post-natal life is late enough to make possible a genetic study of its development; and it persists throughout a span of the rat's life sufficiently long to enable one to observe the alterations with age, experience, and modified conditions of the general metabolism.

In this paper an attempt will be made to set forth salient data concerning: (1) The constituent elements of the copulatory 
pattern of activity and the serial and functional relationships they manifest, and (2) the kinds of external stimuli adequate to initiate the copulatory act and the manner in which their influences are mediated through the receptors. In a subsequent paper data bearing upon internal factors underlying sexual functions will be presented.

\section{Previous studies of sexual behavior}

It will be of value to consider briefly the experimental studies of sexual behavior of the rat and those of other animals, as well, which have a direct bearing on the present study. This literature will be, therefore, the subject of immediate consideration.

Banta ('14) gives an excellent account of the mating of the wood frog. Any moving object which came within the radius of several feet attracted the male and caused pursuit. Masculine aggression was increased or lessened by the response of the object clasped. The vigorous struggles of a male when clasped by another male were followed by relaxation of the clasp and dismounting of the latter. Frequently several males were seen competing for a single female. If one succeeded in getting into a favorable position on the back of the female and fixed his forelimbs firmly about her he usually succeeded, by vigorous kicks of the hind legs, in forcing other competitors to release their holds. Sexual excitement reached its highest pitch at $52^{\circ} \mathrm{F}$. and was almost wholly wanting at $45^{\circ} \mathrm{F}$.

The conjugation of the crayfish was studied by Andrews ('14). He made a very detailed analysis of the pattern of copulatory acts. Seventeen distinct elements were discovered. Apparently the first elements of the pattern were set off by purely local stimuli afforded by other crayfish in the immediate presence of the male. Through the amputation of bodily structures the author tried to ascertain to what extent the later elements of the act would appear without complete expression of the preceding elements. It was found that the later elements were carried on with as much precision as the animal's imperfect mechanical equipment, due to the loss of essential bodily structures, permitted. Recognition of sex arose through trial at 
copulation. The submissive response of the female, as contrasted with the vigorous response of the male, together with the inability to perform the conjugal act on the latter caused the agressor to relax his clasp and to dismount.

The observations of Craig ('14) on the sexual behavior of the dove reared in isolation bring out many interesting points concerning the adequate stimuli for the initiation of the copulatory act. Male doves, prior to sexual experience with female doves, attempted to perform the sexual act upon the hand of the observer. Copulatory attempts were made also upon such inanimate objects as the perch of the cage and the shoe of the observer. When placed with the receptive female very imperfect coördination in mounting attempts were made prior to the successful execution of the first complete act. One male mounted obliquely across the body of the female and failed totally to effect the union. Following the first series of successful consummations of the sexual act a male showed marked alteration in his general behavior, characterized chiefly by increased agressiveness. An irregularity in the pattern of the copulatory act which persisted for many months was noticed in the case of another male. The preliminary billing that usually precedes copulation was entirely omitted by this male.

Kirkam ('13) studied the breeding habits of the rat. His findings indicate that the male, though present at the time of parturition and for several days subsequently, does not kill the offspring. One pair of young rats mated before either was sixty days of age. This seems to be a very unusual instance of sexual precocity. Observations on the copulatory action of brown rats were reported by Miller ('11). He noted that the females in heat did not allow the young males to copulate. Size and ability to dominate were the determining factors. Frequently adult females were seen chasing about the cage small males which had attempted to copulate. When placed with an adult male the same females permitted copulation, offering little or no resistance. He concluded (from evidence that seems quite insufficient) that bodily odors served as a basis for sexual recognition. 
A very elaborate study of the sexual behavior of monkeys and baboons was made by Hamilton ('14). The animals were given far more freedom in their place of confinement than is customary in such studies. Thus reactions closely approximating those found in the natural habitat were observed. Some of the outstanding features of this study are: the great amount of sexual intercourse performed by the males, homosexual tendencies of both males and females, and the use of homosexual behavior on the part of the weaker individuals to divert the attacks of larger males in their attempts at copulation. Under normal conditions of life, the young male, the author believes, does not form habits of masturbation.

Motani ('16) describes the dominating behavior of a male chimpanzee directed toward its cohabitant. When intercourse was desired the male hit the floor of the cage with his hand, whereupon the female approached and assumed the copulatory position before him. Copulation during pregnancy was frequent.

Studies dealing with the reproductive glands as the chief organs exerting a regulatory influence over sexual phenomena are now quite numerous. Although the data of these reports are to some degree relevant to those to be reported in this paper, they can be more advantageously considered in connection with the subsequent study which deals with the internal factors underlying sexual behavior. Such literature will, therefore, be reviewed at a later time.

\section{Technique-General}

The rats were confined in a uniformly heated room. An extra allowance of whole milk was given to the mothers throughout the period of lactation in order to assure favorable conditions for normal development in the suckling young. Approximately half of the litters were weaned when twenty-one days of age; the other half, at the age of twenty-five days. Although the latter gained weight more rapidly, during the subsequent five or ten days, than those weaned at twenty-one days, this difference in rate of gain was only temporary and so small that it was entirely concealed by the individual variations in rate of 
growth appearing prior to the age of sexual maturity. Males were separated from females at weaning time. All were segregated for observation in wire-mesh cages which rested on onehalf inch of wood shavings contained in galvanized-iron trays. When not in observation cages, all animals except those used in experiments involving isolation, were permitted to mingle freely with others of the same sex and of approximately the same age. Individuals kept in isolation were confined in cages of the dimensions 12 by 8 by 8 inches.

Feeding hours were regular and fell daily between 6.00 and 8.00 p.m. The diet, uniform throughout the period of study, consisted of white bread and whole milk served together in small tin containers during six days of the week. On the remaining day a grain mixture (McCallum diet), made into a mash by the addition of water, was substituted for the bread and milk. Once a week fresh cabbage leaves were added to the above diet. Weight records were taken at five-day intervals or oftener in experiments requiring more detailed records of weight.

The animals whose sexual behavior was observed from day to day were removed from the housing cages to individual observation cages ( 12 by 8 by 8 inches) from four to six hours prior to the time of observation. The purpose of isolating the animals was to allow time for each to become thoroughly cage-adapted, thereby reducing random cage exploration to a minimum during the period of observation.

In general, the method of studying the sexual behavior of the young animals was systematic observation of normal and operated animals in confinement. Special methods and technique employed in particular phases of the work will be described in detail in connection with the report of experimental data in the following sections of the paper.

\section{THE COPULATORY ACT}

The constituent elements of the copulatory act are well coordinated at the time of the initial copulation. No more fundamental problem confronts the student of animal behavior than that of discovering the process by which these constituent ele- 
ments are integrated into a complex unitary pattern. By the elucidation of this process an important step will have been taken in the analysis of the changes through which elementary activities are being combined and dissolved continually in habit formation throughout the lifetime of living organisms.

A preliminary basis for the study of the integrative process may be established by resolving the copulatory pattern into its chief constituent activities and then ascertaining whether these elements appear in isolated or partially isolated function during the prepuberal life of the young animal or whether they appear for the first tìme as parts of the complex copulatory pattern. This has been done by observing the prepuberal activity of the young male under natural and experimentally controlled situations. The presentation of these data may be simplified somewhat by considering at the outset the copulatory act of the sexually mature and experienced male. This consideration will furnish an adequate basis for the examination of the prepuberal activities and the initial copulatory act of the young male.

\section{Copulatory act as seen in the mature rat}

One cannot give a detailed description of the male's sexual activities without taking into account the pattern of feminine activity by which it is initiated and toward which it is directed. That is to say, the conjugal act as a whole involves both a masculine and a feminine pattern of activity, the elements of which have a relationship of functional interdependence, and are themselves, acts of a high degree of complexity. The elements of each pattern appear in serial order and are so synchronized that elements of one pattern act in harmony with those of the other. And thus through mutual furtherance they run their courses in the wonderfully complete and well coördinated manner seen in a cross-sectional view of the reproductive process.

When a female is placed into the cage of a potent male that has been thoroughly cage-adapted, the latter begins in a few seconds to examine her ano-vaginal zone. Smelling and licking occur irrespective of oestral cycle, and the amount varies with a given individual from day to day. The non-receptive 
female, thus placed does a variable amount of cage exploration. While doing this, she is followed by the male with his activities directed almost wholly to her. If he is too vigorous in vaginal sniffing, nibbles too deeply in search for parasites, or impedes her progress by playful assaults, she sometimes resists with a back-kick of the hind foot, or by moving into a corner of the cage where she is less accessible to his assaults. The receptive female usually makes a less extensive round of exploration. When approached by the male in the manner described above, she assumes a tense attitude that involves the general musculature of the body and limbs, Frequently this tension is accompanied by slight vibratory movements of the head and shoulders sufficiently general in its distribution to give to the whole body a shivering effect. The shiver may last from one to two seconds. After a moment of smelling or licking, on the part of the male, the receptive female runs forward in the cage a short distance or bruskly shifts her position so that the root of her tail is directly in front of the male. This running movement resembles the quick irregular gallop of the guinea-pig. If the male is sexually aroused by this movement and pursues her across the cage, as is usually the case after she has moved one or more times, she runs only a short distance and halts upon being overtaken by the male and caught in the copulatory clasp. She halts instantaneously when firmly clasped.

Although the responses just described are typical, there are many variations from this type. Some females, persistently, and nearly all observed at the onset of the oestral period, re-act to the vaginal smelling and licking by running wildly about the cage, kicking with the hind foot, and, not infrequently, biting at the pursuer.

In many cases the male begins to copulate within the first minute after the female is placed in the cage. In some instances, however, a variable number of pre-copulatory activities of short duration precedes the act. These activities, for the most part irrelevant in nature, occur in promiscuous order. (They never suggest a type of courting behavior.) The acts appearing most frequently are: nibbling at the head or body of the female, 
repeated licking and smelling in the ano-vaginal zone, scratching his own body, and momentarily sniffing at the wires of the cage. Rarely, at such times, he stops to lick the penis. The copulatory act, when it does appear, comes with such definiteness and orderly sequence of elements that it stands out in marked contrast and is never confused with this background of promiscuous activities. It is an organized unit of behavior that runs its course with great smoothness when the first element of the series is set into action.

In the act of mounting, the male clasps the sides of the female with his fore-paws encircling her body just posterior to the short ribs. The palmar surfaces of the fore-paws are directed medialward, in a dorso-lateral, lateral, or ventro-lateral position on the female's sides, varying with the size of the female and the girth of the male's fore-limbs. Simultaneously with the clasp, or following so closely that no time interval is discernible, rapid vibratory palpation of the female's sides occurs. To the palpatation, the female responds by depressing the back deeply in the lumbar region. This movement simultaneously elevates the coccygeal region with the hip-joint serving as a fixed pivot of rotation. The elevation of the coccygeal region raises the external orifice of the vagina from the floor of the cage to a height more accessible to the male, and at the same time, throws the axis of the vagina into a plane conforming with the direction of piston movements of the penis when vaginal entrance is attempted.

Following the palpation of the female's sides, which serves as an adequate stimulus for the depression of her back with consequent elevation of the coccygeal region, the male makes a series of rapid movements of the pelvic region which serve to direct the erect penis into and out of the vagina in piston-like manner. With the consummation of the orgasm the palpation and piston movements cease and the male throws himself from the position assumed in mounting by a vigorous backward lunge that clears his body from that of the female by a distance of from three to five or more inches. With the backward lunge he comes to a sitting position with the weight of the body sup- 
ported on the root of the tail and toes of the hind feet. At the same time the mouth is brought down to the penis which is still in a semi-erect condition. Vigorous licking of the organ follows. After a few seconds licking the organ becomes flacid and is retracted into its sheath and the male comes to a position of rest on all fours where he remains quietly for a short time or engages in minor activities such as nibbling at parasites, scratching the body, or sniffing warily at the female. Smelling and licking in the vaginal zone is seldom repeated after the first two or three copulatory acts.

By way of summarization of the foregoing description the overt pattern of the copulatory act may be broken up into the following elementary acts or groups of activities:

1. Pursuit and mounting.

2. Palpation of the female's sides.

3. On the part of the female, depression of the lumbar region of the back with consequent elevation of the sacro-coccygeal region.

4. Pelvic movements of the male by which the penis is thrust toward the vagina in piston-like manner.

5. Cessation of palpation of female's sides and the backward lunge.

6. Licking of the penis.

The duration of the complete act, from the time of the initial clasp to the backward lunge is usually only a fraction of a second. The time is so brief that one cannot measure it accurately with a stop-watch. In each instance of its appearance, the pattern is strikingly uniform, yet close observation reveals some minor irregularities. A few of these are deserving of mention.

Piston movements by which vaginal entrance is effected do not invariably follow palpation. Sometimes, apparently, this is due to failure in eliciting coccygeal elevation on the part of the female, but again it seems to be due to failure of erection. Evidence of the latter is seen most frequently during a long series of copulations. The number of such instances increases with the number of copulations. 
Withdrawal, as a rule, is made immediately upon the consummation of the orgasm, but in the case of males copulating for a somewhat prolonged period of time, there occurs now and then an instance of failure or retarded withdrawal after cessation of piston movements. Prolongations of from one to five seconds have been observed. In these cases the withdrawal is effected by the male alone, with the elimination of the backward lunge, or by the female's jumping forward and slipping from the relaxed clasp of the male. One female on the occasion of tardy withdrawal invariably squealed sharply and turned savagely on the male, striking at his head with her fore-paws or viciously biting at his face and shoulders.

\section{Sexual behavior of the young rat}

The sexual behavior of approximately fifty young males and three young females was observed in this study under ordinary cage and experimentally controlled conditions. Before considering the data gathered in these observations the methods used in systematically sampling the behavior of certain young males and females will be described.

Two series of systematic observations on young rats were made during their prepuberal development and for a short time thereafter. These series differ somewhat in type and serve to supplement each other. In the first series 15 males and 3 females were observed from the age of thirty days to the age of somatic maturity. The group consisted of the following animals: 6 normal males; 3 normal females; 2 blind, 4 anosmic, and 3 castrated males.

The fifteen males were confined in a large cage ( 18 by 20 by 30 inches) while not in their individual observation cages. The females were kept with a group of from two to four females of the same age in a smaller cage (10 by 16 by 14 inches). Daily all were isolated in individual cages for a period of from four to six hours prior to the time observations were made. Between the hours of 5.00 and $8.00 \mathrm{p} . \mathrm{m}$., when the animals are normally very active, a female - non-receptive ${ }^{1}$ as a rule, but receptive when

1 The term non-receptive is used to describe females that would not copulatefemales not in heat. 
available-was placed in the cage with a male. The young animals were observed individually, upon the introduction of the female, for periods varying from five to fifteen minutes daily, or longer if the activity of the young animals made a prolonged period of observation desirable. Notes pertaining to the general types of activity, the aggressiveness or lethargy of male or female, etc., were made. Also points of a more specific nature were looked for, such as: smelling and licking the ano-vaginal zone; attempts at sucking; nibbling at the sheath of the penis; unsheathing, licking and manipulating the penis; rhythmic extrusion and retraction of the penis in the sheath; mounting and palpation of the female sides while in the copulatory position; playful attempts at copulation prior to the age of sexual maturity.

In the second series of observations the method was varied to bring out more details on certain points not revealed in the previous study. In the first series quantitative data concerning the kinds of activities and their duration were not secured. Furthermore, there was no control over the activities aroused by mingling with other animals of the same age while not under observation.

In the second series 8 animals, 6 males and 2 females, all of the same litter, were used. It was a well nourished litter and the young were able to subsist on a bread and milk diet at the age of twenty days. When twenty-one days of age the young were weaned and isolated in individual cages where they were kept during the entire period of study. Under these conditions they had no opportunity to mingle with other animals, except while with the adult during the period of observation. On alternate days the behavior of each animal was studied and records were made which gave the type of activity and its duration in each minute of a twelve-minute period.

A simple scheme for recording the behavior was devised. All the types of activity that had been observed during the first study were listed. Certain acts of a similar nature were thrown together in order to reduce the number of categories as much as possible, yet keeping separate all acts of a doubtful or definitely sexual nature. Obviously this catalogue is devoid of logical 
arrangement and the range of its usefulness is limited wholly to the needs of the problem at hand.

When the list of categories was satisfactorily arranged and pruned down to workable proportions a number was given to each of the items; this was to be used later as a symbol for that item. Then the categories and the numbers that stood for each were thoroughly memorized and tried out in practice for a short time upon other animals. With stop-watch in hand the observer recorded chronologically in one column of the record blank the time of incidence of each activity and in a column beside it the appropriate number to denote the category into which it fell. Obviously the time at which each new act began marked the end of the old act.

From these records the exact duration of every act during each minute of the twelve-minute period was computed. This gave a record of the type of action, its duration, and its relation to other activities in the twelve-minute period. The table that follows gives the catalogue of activities used, together with a code-form or abbreviation that will be used in the tabular reports of the data from the observations.

The young male rat, whether mature or immature, if thoroughly tame and cage-adapted, usually loses no time in approaching the female when she is introduced into the cage. Almost invariably, in these observations, he was at her side before all her feet were implanted on the floor of the cage. He proceeds in a direct and thoroughgoing manner to explore the female by sniffing and licking, nibbling and nosing her body in various places-activities which readily cause the receptive female to betray, by actions easily recognized by the experimenter, her condition of receptivity. Evidence of sexual excitement is manifested by the male, as a rule, in the first five or ten minutes after the female is placed in the cage or not at all. Hence for practical purposes, it may be assumed that if the animal under observation does not show signs of excitement during the first five or ten minutes, providing he has thoroughly explored the female during that time, he will not ordinarily show signs in from onehalf to one hour or more of observation. This practical rule is 
founded on numerous observations for periods lasting from onehalf to one hour, on over fifty young males used in the various phases of this study.

TABLE 1

\section{LIST OF CATEGORIES USED IN RECORDING THE BEHAVIOR OF
YOUNG MALE WTTE ADULTB}

1. Nibbling at head, neck, body and limbs from any position; sniffing and nosing or licking at any region of female's body other than elbows and vaginal and anal region .....

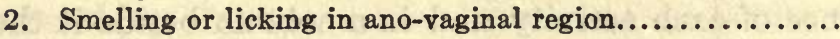

3. Exploring cage, nibbling at foreign matter in cage, climbing about cage, and running in cage not involving pursuit or escape from female.......................

4. Following female as she moves about cage with head in close proximity.

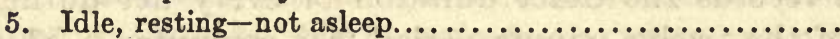

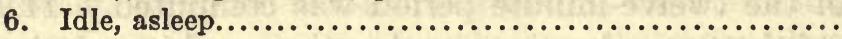

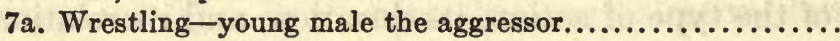

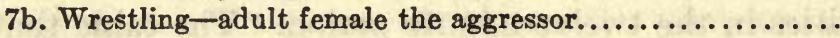

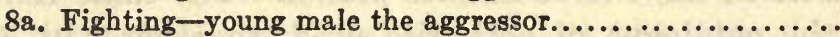

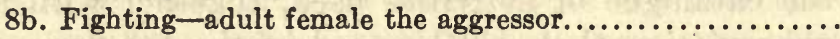

9. Nibbling, kicking, or scratching own body, other than

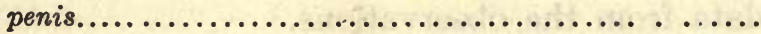

10. Licking penis, or young female licking external genitals... 11a. Female sniffing, licking, or nibbling body of male other than genital organs-male passive...................

11b. Female sniffing, licking, or nibbling genitals of male......

12. Reciprocal sniffing, licking, or nibbling genitals..........

13. Fear response, in which male assumes definite physical

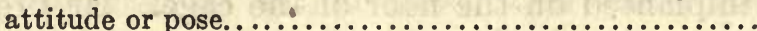

14. Mounting, involving clasp and palpation of female's sides

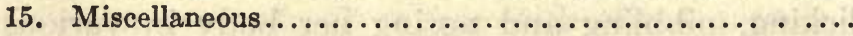

16. Fear response of male in which pose is not assumed. Remains stationary or moves about cage..............

17. Nursing or attempts at nursing..................

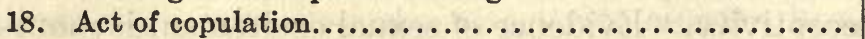

19. Smelling or licking right elbow (hair saturated with aqueous solution of pituric acid) ......................

20. Smelling or licking left elbow (control)
ABBREVIATED CODE

Nibbling

Licking

Cage explor.

Following

Idle-awake

Idle-asleep

Wrest.-young

Wrest.-adult

Fight.-young

Fight.-adult

Scratching

Lick.-penis

F. lick. Body

F. lick. Genit.

Recip. lick.

Posing

Mounting

Miscel.

Caution

Nursing

Coition

Rt. Elbow

Lt. Elbow

By this method of observation, the behavior of young males with the female has been sampled from day to day throughout the period of development from weaning to sexual maturity. It 
is believed that the samples, taken collectively, give a very fair picture of the general nature of the activity of the young rat in the company of the female at various ages prior to sexual maturity. It, will, therefore, serve as a tentative basis for the consideration of permature sexual behavior.

A. Prepuberal behavior. Tables 2 to 11 give the data for each of the eight rats used in the study. Rats 50 and 54 were observed daily. On alternate days an adult male was substituted for the female. The other six animals were observed on alternate days, and with females only. The data for two consecutive observations have been combined and averaged in order to condense the results somewhat, thereby giving a more compact picture of the types of behavior to which attention will be called. The numbers give the time in seconds spent by each rat during twelve minutes doing a particular act or class of acts grouped under a heading of the category.

For the purpose of briefly considering the relation of the foregoing prepuberal activities to the copulatory act they may be thrown into two groups: (a) A group of non-sexual, or acts that are obviously unrelated to the copulatory act; and (b) a group of acts that appear to be connected with the copulatory act but are really not so connected. Under these headings the chief facts brought out in the two series of observations may be considered.

a. Non-sexual activities. The young rat, twenty-one days of age, gives attention to the adult female as soon as the latter is placed in the cage. It approaches without fear and procedes to explore such parts of her body as are within reach. From three to five days later it climbs upon her back, if she sits quietly in the cage, and extends the general exploration to the back, neck and top of her head. Sniffling in the region of the mammary glands is seen occasionally at or a few days after the age of twentyone days, but only rarely after twenty-five days. The greater part of the time during the first five to ten minute is spent in nosing about the head of the female, licking her body, and searching for parasites (Nibbling, tables 2 to 11.) This holds true for all ages from the time of the first observtions to the last. While 


\begin{tabular}{|c|c|c|}
\hline 3 & MOQIII $\mathrm{LIT}$ & \\
\hline$\infty$ & мовтт 'บ8 & 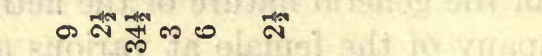 \\
\hline & Noturos & 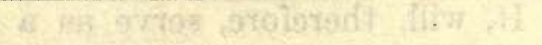 \\
\hline בั. & ONISYaN & \\
\hline$\frac{20}{2}$ & 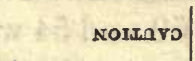 & HA9L ำ \\
\hline ล & วसОรIx & 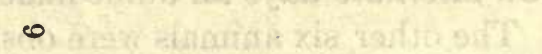 \\
\hline 0 & DNIRNaOK & 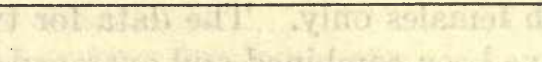 \\
\hline$\stackrel{\widetilde{్}}{\mathbb{E}}$ & ONIsOd & $1017=$ \\
\hline 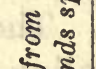 & 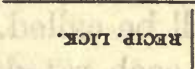 & $=4$ \\
\hline స్త & - IINTE HDIT A & $\underset{H}{*} \oplus \infty \quad$ or \\
\hline & 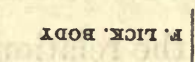 & 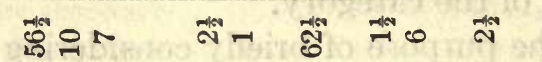 \\
\hline 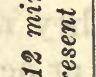 & gINad ' YDIT & เ 0 음유 \\
\hline . हू & ONIHarvzos & 푸웍 \\
\hline r & uradr-ingrs & 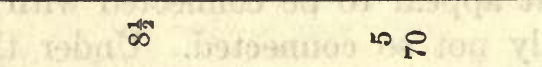 \\
\hline हूँ & DNAOX-IHOIA & 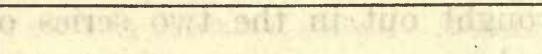 \\
\hline & 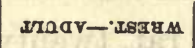 & \\
\hline कूँ & ONAOX-IST\&M & 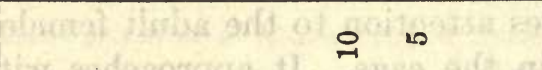 \\
\hline .స వ్రి & dIIT8V-aTaI & in \\
\hline 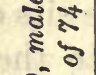 & 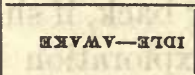 & สื \\
\hline$\underset{8}{\square}$ & DARMOTTOA & N N" \\
\hline వर & 'หojdXa gDvo & గ゙丨 \\
\hline हूँ & ONIYOIT & 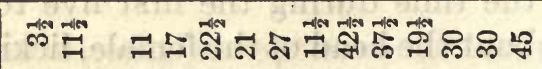 \\
\hline bे & DNITRaIN & 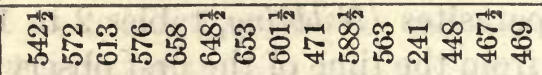 \\
\hline$\stackrel{\overrightarrow{0}}{\stackrel{7}{*}}$ & gLVa NI gOV & 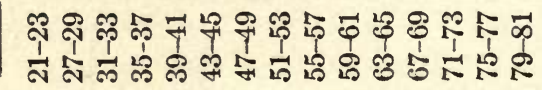 \\
\hline
\end{tabular}




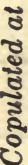

$\stackrel{0}{8}$

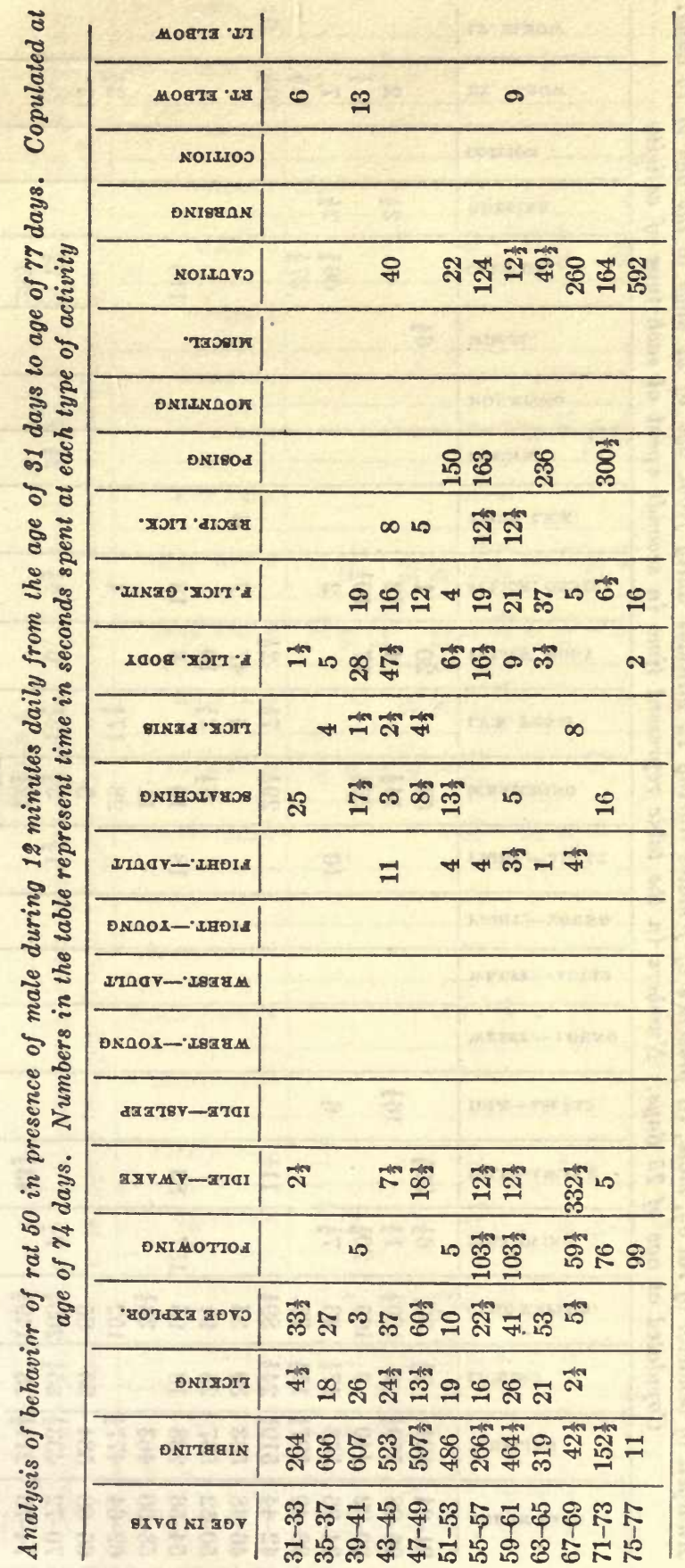




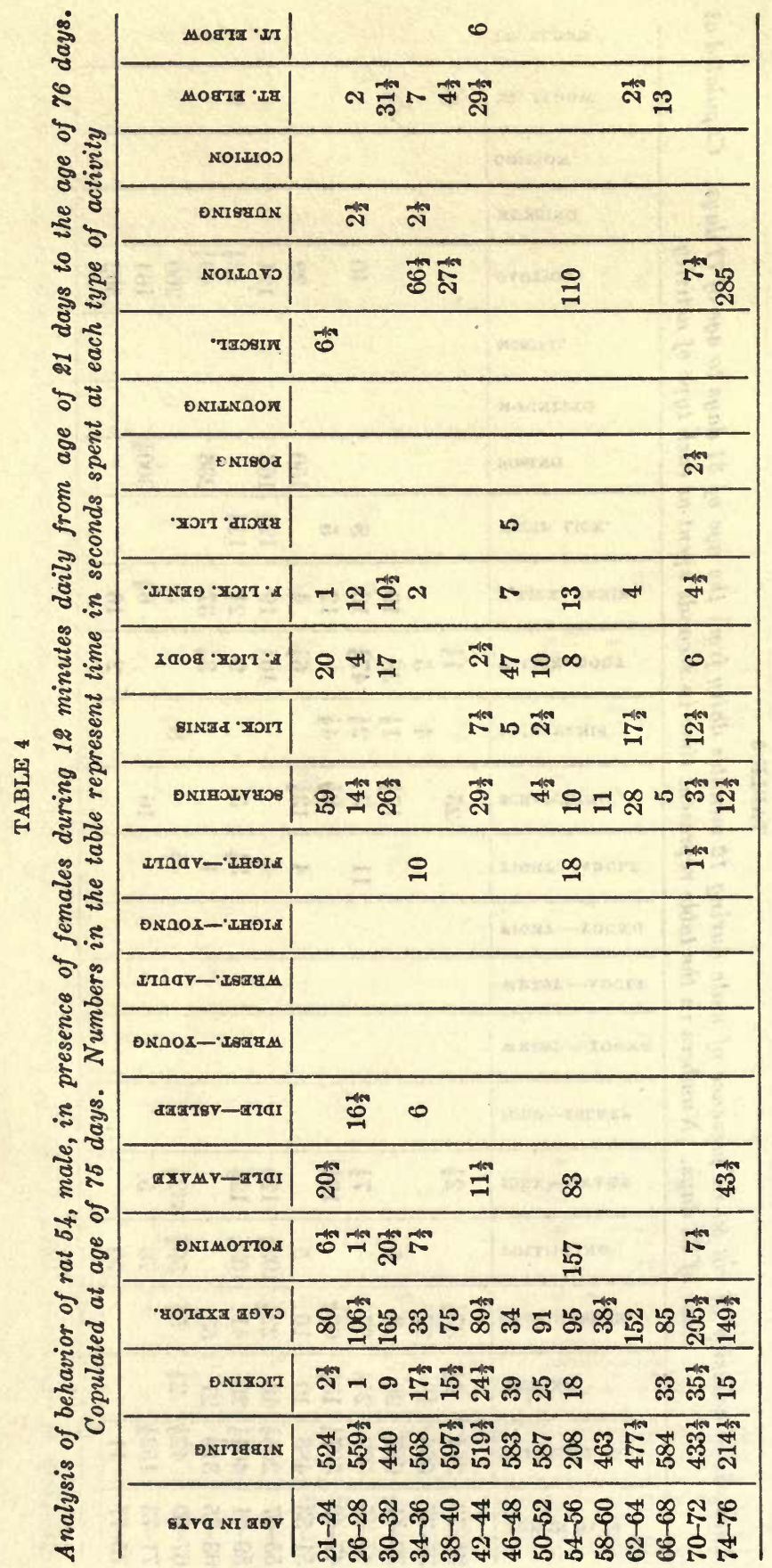




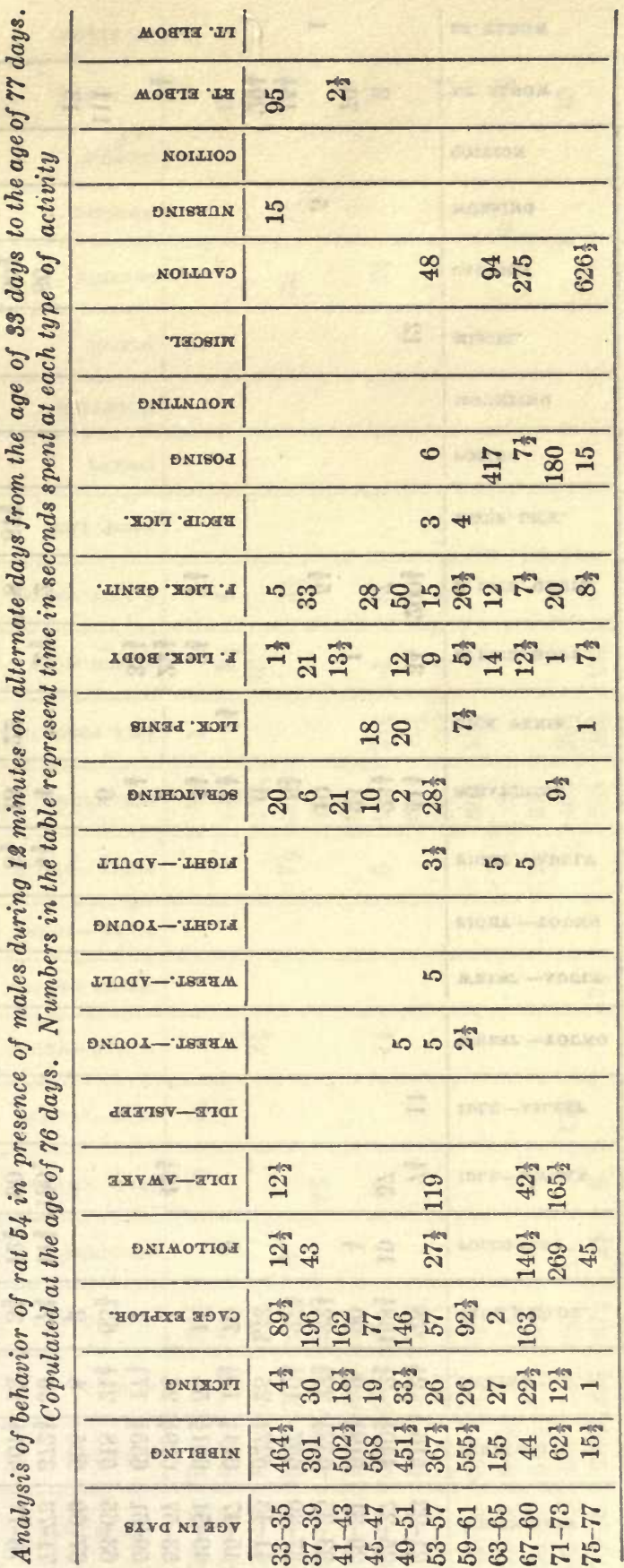




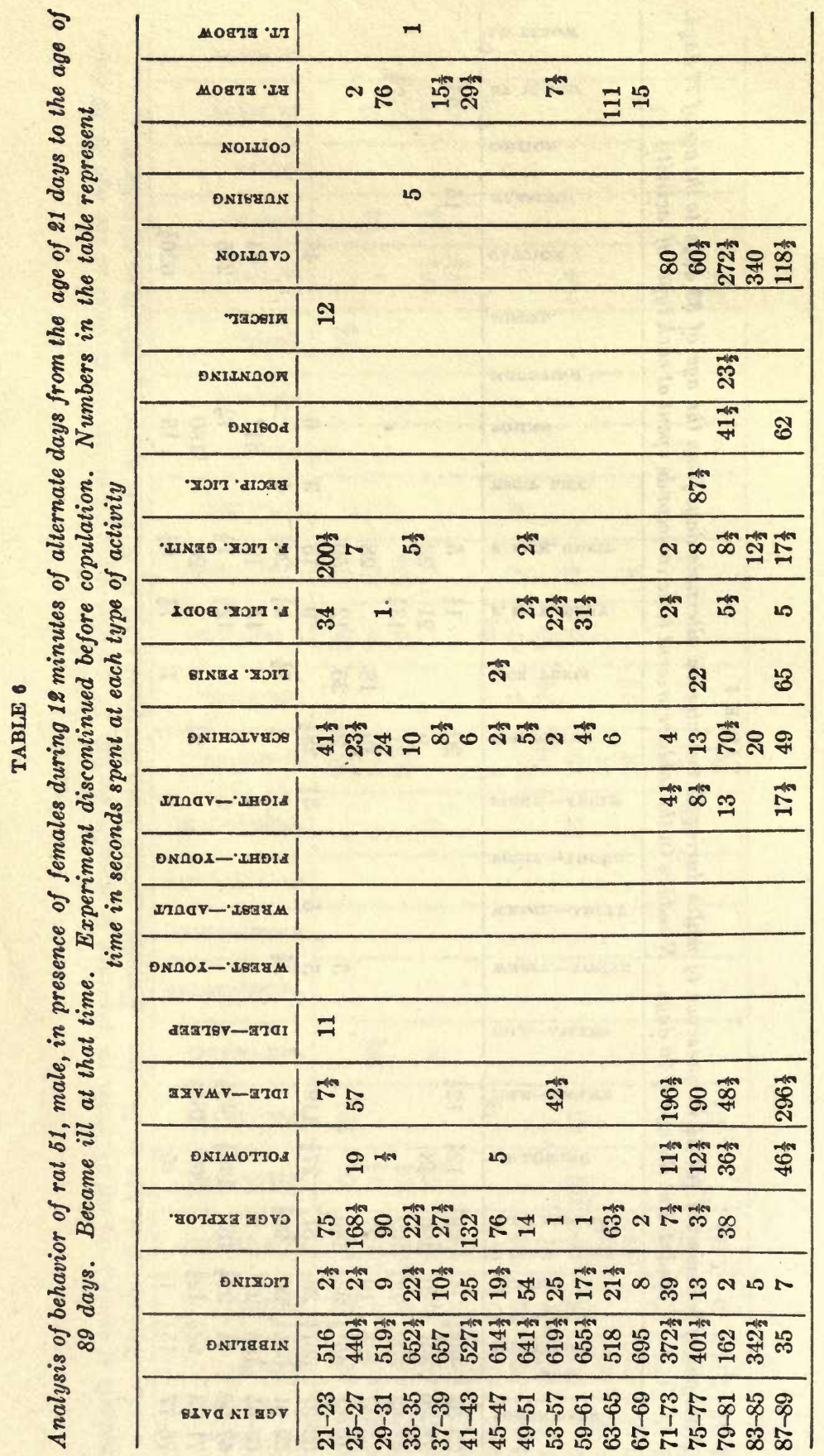




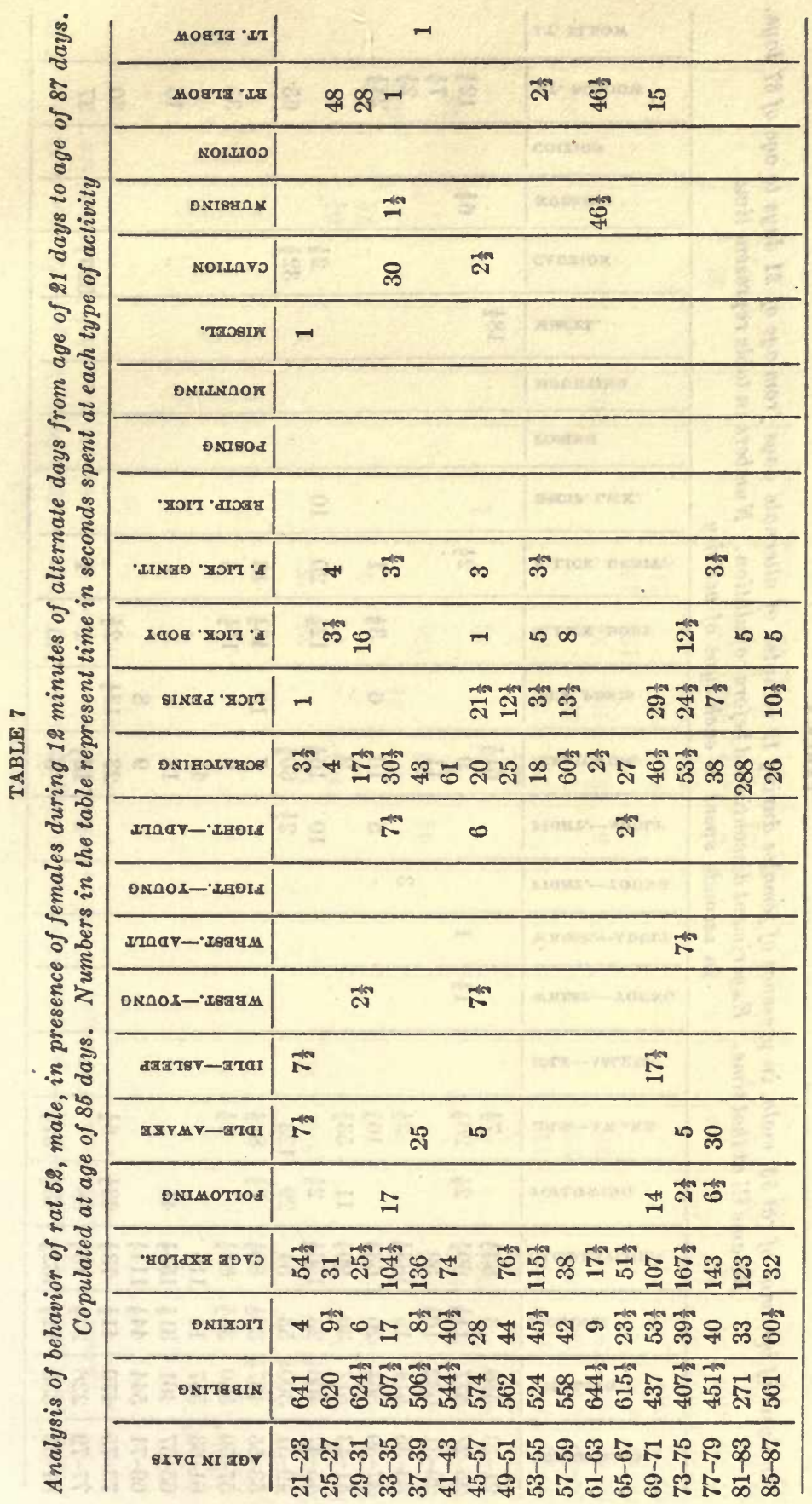




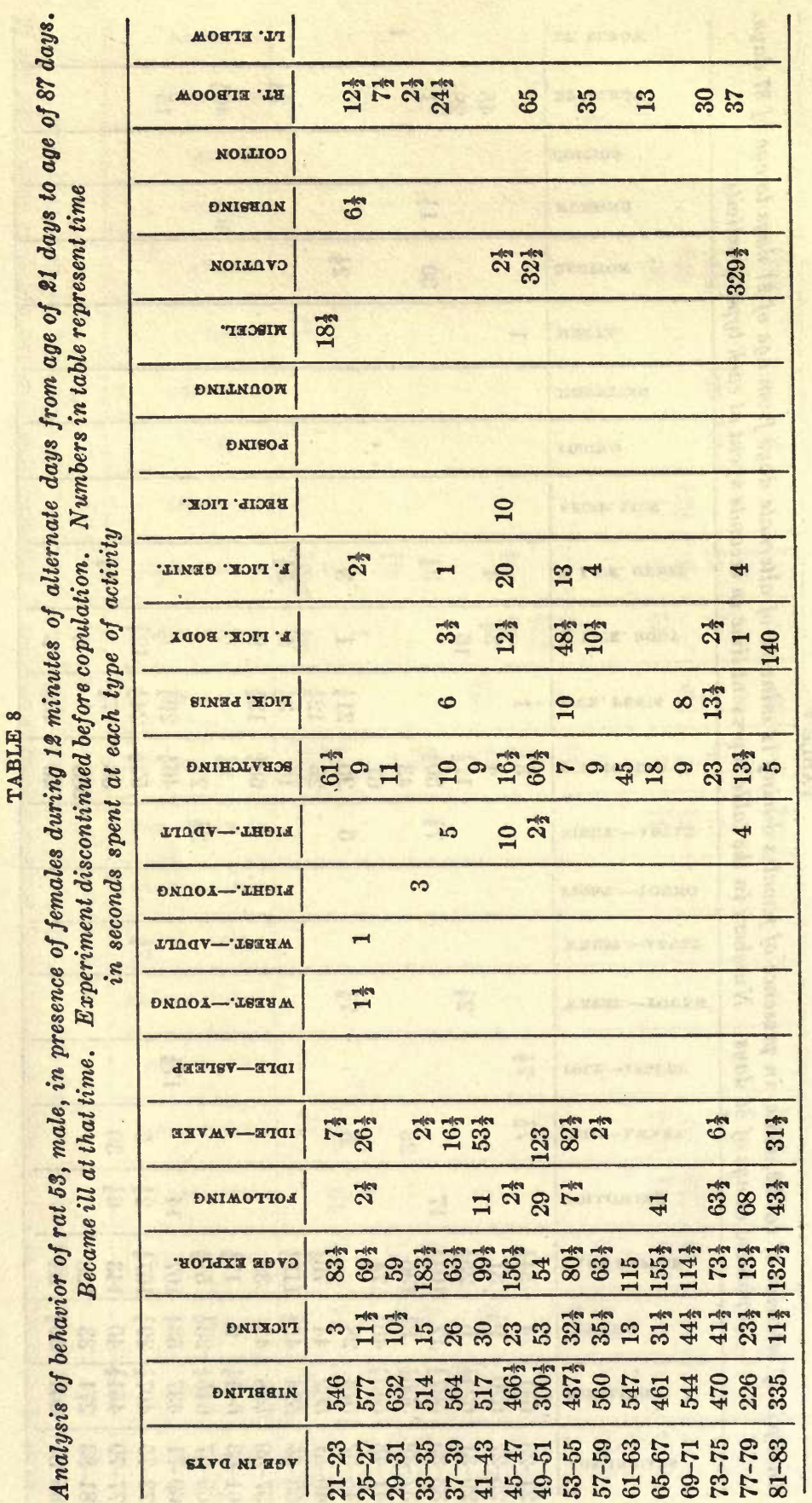




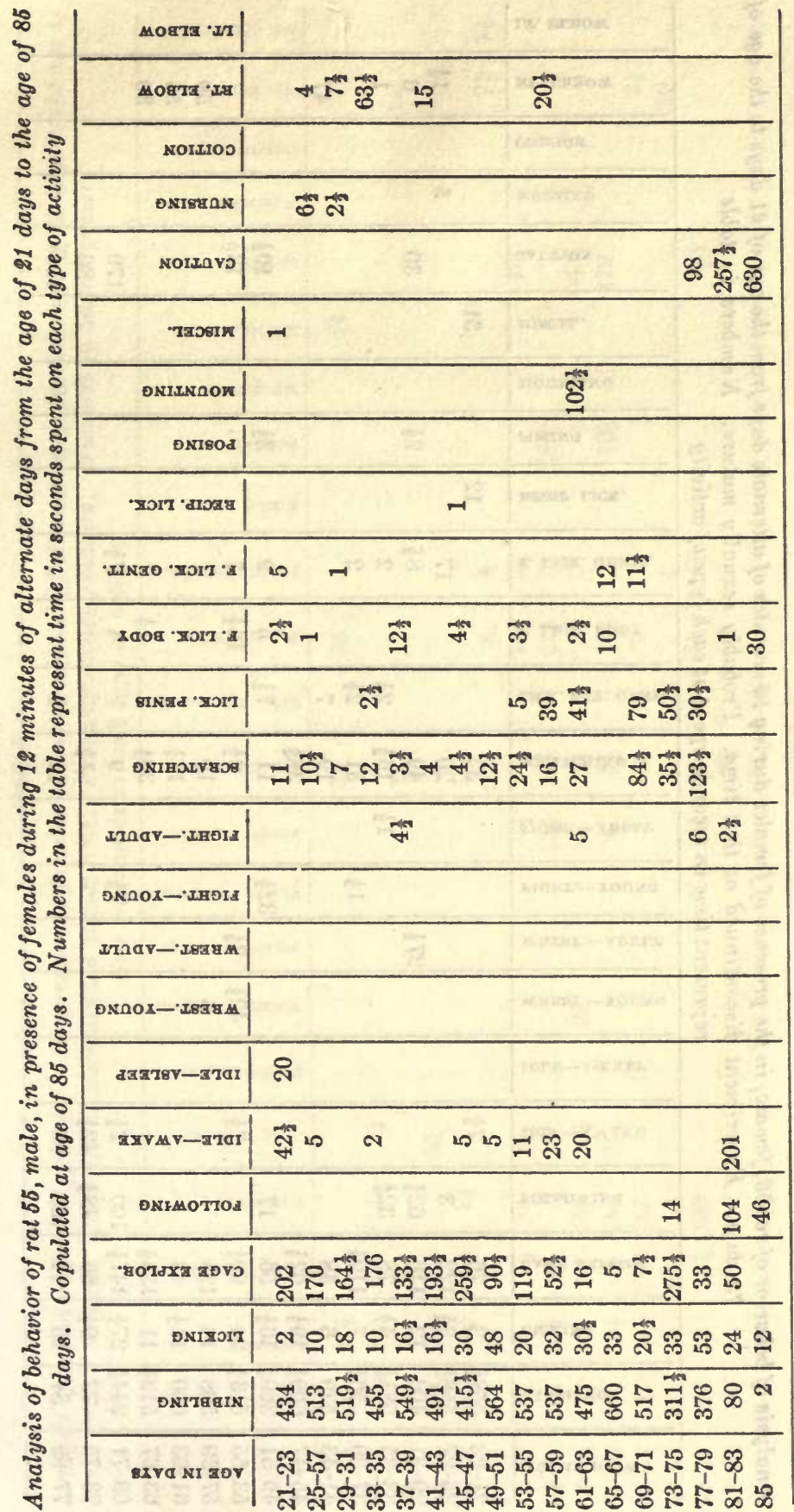




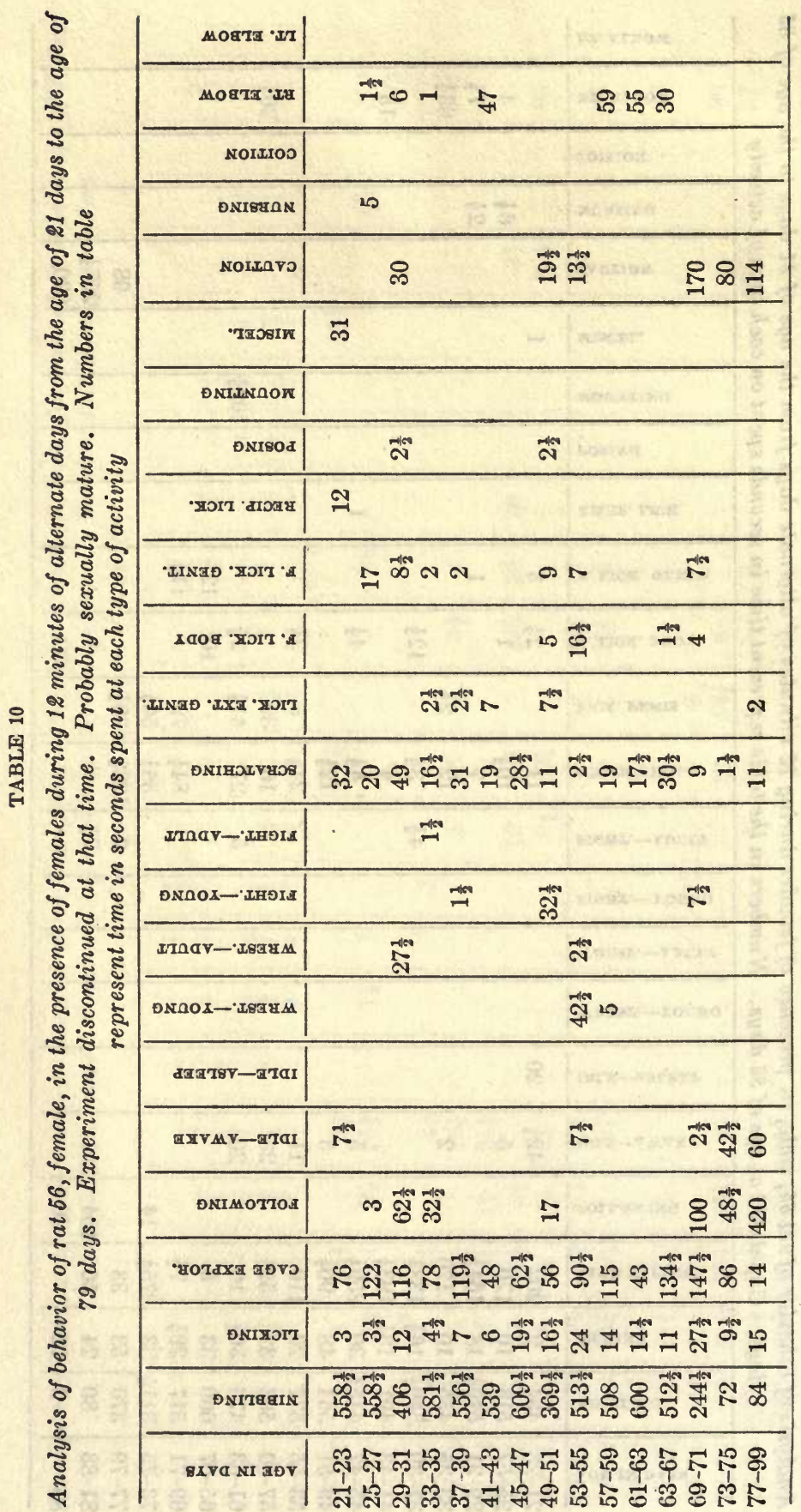




\begin{tabular}{|c|c|c|}
\hline $\begin{array}{ll}0 \\
2\end{array}$ & мовтз 24 & H1 $=0$ \\
\hline 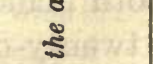 & MO873 'x2 & ซี \\
\hline & Noruroo & 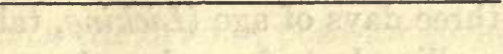 \\
\hline है & oxarzan & $\rightarrow$ \\
\hline ○. & Norravo & 2 2 ฬ ำ \\
\hline 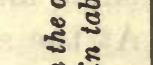 & 7asom & 97962945,20 \\
\hline & oxrasnor & \\
\hline वृ & oxusod & 茼 \\
\hline 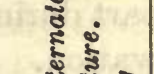 & 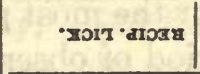 & 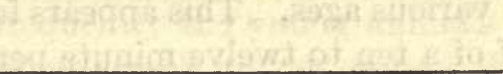 \\
\hline రేँ & HINGD 'MOIT $A$ & 20 \\
\hline 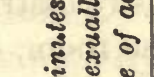 & $2008 \cdot 2015 \cdot A$ & ஜ \\
\hline 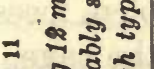 & 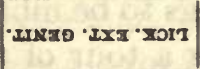 & 120 \\
\hline 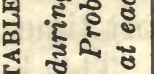 & омIнатVвов & R \\
\hline & 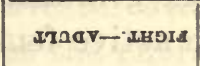 & ก \\
\hline & oxnox-shola & \\
\hline 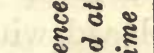 & 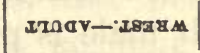 & \\
\hline है. & ONDOX-I.SGYM & ชิ \\
\hline . స్ & dXargv-aTar & \\
\hline 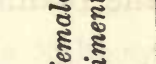 & $\operatorname{arv} \Delta \mathrm{V}-\mathrm{graI}$ & * \\
\hline 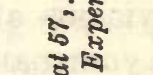 & ONIMOTTOA & ำ \\
\hline$\dot{0}$ & 'goTdx马 zovo & స్ \\
\hline$\frac{1}{20}$ & ONIrXIY & 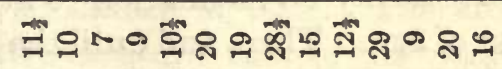 \\
\hline & DNITEGIN & 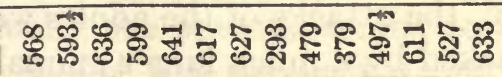 \\
\hline & gxtanimot & 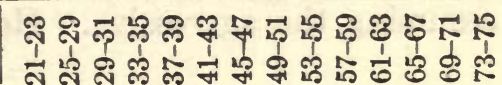 \\
\hline
\end{tabular}


nosing about the body of the female the young animal discovers the chief sources of secretions and excretions. Both males and females begin to smell in the vaginal region when twenty-one to twenty-three days of age (Licking, tables 2 to 11).

The smelling lasts for only a few seconds until approximately twenty-eight to thirty days of age, when the individual periods of smelling lengthen somewhat and the total amount of smelling during an observation is also increased by only a small amount during the remainder of the prepuberal period. At the age of thirty to thirty-five days, smelling is begun within a few seconds after the female is placed in the cage.

The amount of time given to cage exploration is fairly constant at various ages. This appears for the most part during the last half of a ten to twelve minute period of observation. After the young rat has thoroughly explored the female her presence has less stimulating effect on it, hence it is more easily distracted by stimuli coming from other sources-noises in the room, odors from the walls of the cage, loose shavings to be nibbled, feces, etc.

Frequently the female, after making a tour of the cage, gives her attention to the young in the cage for a short time. She nibbles and licks his body and smells his genitals. This is done at every age of the young male. The active females most frequently stop to smell the genitals of the young. Sometimes the two are seen smelling each other's genitals simultaneously. This occurs most frequently when an adult male is placed with the young animal.

Attempts at nursing were seen during a few observationperiods after the young animals were weaned. These attempts consisted chiefly of sniffling and nibbling about the mammary glands.

In no case was a young male seen to launch a vicious attack on an adult female. Being attacked, however, the young animal sometimes defended himself. The adult female and adult male showed practically no inclination to attack young animals under forty days of age. Then, and until the observations were brought to an end, the attacks of the adults were frequent.

If attacked by a much larger animal the young rat seldom resists by assuming the aggressive. He takes up a defense pose 
which enables him to guard against the attack of the aggressor and indicates to the latter that no counter attack from him is to be expected. Sometimes after the adult ceases pummeling the young animal, the latter holds the defense pose for several minutes (Posing, tables 2 to 11 ). Particular attention is called to the amount of posing done by the young animals in company with adult males (tables 2 and 3 ). Contrast with tables 4 and 5. The adults show increased tendency to maltreat the young after the latter have reached the age of forty to fifty days (tables 3 and 5). Item 16 which is another phase of the defense response, characterized by cautiously avoiding the adult, shows that the attacks of the adult cause responses which carry over from day to day. Not infrequently the young animals showed this fear response, although no attack on the part of the adult had been made or threatened during that period.

Wrestling is initiated both by the adult and by the young. It was an activity of daily occurrence in the case of the first group of twenty-three animals; they were allowed to mingle together while not in the cages for observation. The eight animals of the second group, which were reared in almost total isolation seldom attempted to wrestle with the females. It appears that this activity acquires the characteristics commonly seen in the play of young rats only through experience.

The amount of time spent in following closely behind the adult without actually smelling or nibbling depends somewhat upon the general activity of the adult. Most animals continue their smelling and nibbling while the adult moves about the cage, but occasionally one follows without actually touching the adult's body.

In a subsequent chapter the purpose of the experiment involving the placing of a weak solution of pituric acid on the left elbow of the female will be discussed at greater length. Attention is called at this place to the fact that all young animals discovered the oderiferous substance at once. The amount of smelling in this region greatly exceeded that of the vaginal zone for several days, but gradually the amount ceased to increase and eventually decreased; finally this region was not smelled 
by some animals at all during the periods of observation ( $L t$. Elbow, tables 2 to 11 ).

b. Acts that appear to be related to the copulatory act. At all ages the young animals stop any activity in which they are engaged to bite and scratch parts of their bodies. The amount of scratching varies from day to day and shows no regular tendency to increase or decrease at particular ages. Associated with scratching of the body is the nibbling of the external genitals which, in the case of the males, eventually comes to be chiefly the licking of the penis. The amount of licking of the genitals increases in amount from the age of thirty-five to forty days and is seen frequently thereafter until the age of puberty is reached. Casual observations lead to the conclusion that it is continued throughout the period of potency of the male. In the case of rat 52 , a well developed male for his age, about $2 \mathrm{~mm}$. of the glans penis was seen protruding from the prepuce at the age of forty-two days while the male was vigorously licking and nibbling the sheath, using his fore-paws at the time to manipulate the organ into positions favorable for licking. With age the tendency for the penis to protrude while licking becomes greater because of development in size. Thus, accidentally at first, the tongue is brought into contact with the sensitive glans penis. The stimulating effect of licking probably causes the act to be repeated and to become habitual. Whether or not this act may be considered a form of masturbation in the rat is an open question. It is well known that the tongue and oral mucosa in contact with the penis of man is capable of arousing the reflexes concerned with ejaculation. (Ellis, vol. 11.) In the case of the rat, however, no case of orgasm has been discovered as a result of the licking of the organ, but the difficulties of detecting the orgasm are such that one cannot be sure that it is not effected. The vigorous movements of the pelvis seen in some instances of the licking and the use of the fore-paws to manipulate the sheath suggest that these acts aid in producing the maximum stimulation of this organ while licking is in progress. No evidence was found which indicated that it aids in the initiation of the first copulatory act. 
With respect to young animals it has been suggested that many of the play activities anticipate the larger acts that are to be performed by the adult for the preservation of self or the species. Groos ('95) interprets the mounting seen in some animals in infancy as anticipatory practice in the reproductive function. Careful watch was kept for this in the young male rat, but no mounting of the kind done by copulating males or males during the period of pre-copulatory activity was noticed. Two male rats that were over seventy days of age which had not had sexual congress were observed, however, to mount cage-mates in the definitely sexual manner, and attempt a complete copulatory act. Small ('99) speaks of the playful sexual activities of rats under thirty days of age. Our own study does not substantiate his observations. When receptive females were placed with the young males the latter showed no definite sexual excitement until approximately 70 days of age. Prior to that time the smelling of the vaginal region of receptive females was sometimes more extensive than with normal females, but that may be accounted for by the tendency of young rats to smell at any new odors that are introduced. The secretions of the vagina at the time of the oestrum give rise to new olfactory stimuli to be examined, hence the periods of smelling when females in heat are introduced into the cage are somewhat longer.

B. Initial copulatory act. The initial copulatory act of the young male resembles that of the experienced adult so closely that differences are not easily discerned. Using as a background the descriptive account (pages 101-105) of the copulatory act of the adult, one can get a fairly complete picture of the initial copulatory act of the young male by considering the differences between the two.

a. Copulatory act of the young male contrasted with that of the adult. Two kinds of differences between the act of coition of the adult and the young have been found occurring with a fair degree of regularity. The first consists of differences that arise from structural limitations - size, girth of forelimbs, and general bodily vigor; the second, of differences which result from the shunting of sexual behavior by fear responses or dif- 
ferences that appear to arise from slightly incomplete coördination of the elements of the complex mechanism involved in the copulatory act. Differences of the first type, being relatively unimportant for this study, will be passed over with only brief remarks as to their nature.

Limitations in the size of the male and the girth of his forelimbs cause a slight difference in the placement of the forepaws on the body of the female as he stands in the copulatory position. Difference in strength of the fore-limbs results in palpation less vigorous than that of the adult. The palpation suffices, nevertheless, to elicit the necessary coöperation of the female. Frequently the backward lunge of the young is greatly reduced in force or even eliminated entirely - the male slipping smoothly from the mounting position.

The second group of differences between the experienced male and the novice needs more careful consideration for it embraces factors that are concerned with the initiation of the copulatory response. During the tests for copulation in young males fear responses, aroused by an attack or threatening attitude of the female, caused the male to move as far from her as the space in the cage permitted. There he remained quietly but on guard against further assault. These responses sometimes last only a few minutes, but in other cases more than an hour. Young rats which had recently been pummeled or bitten severely by adult rats during the daily observation periods sometimes exhibited fear responses to the quick movements of the receptive female in the cage. Such fear responses were sometimes aroused by very docile females which were responding to the male's nosing and licking with the spasmodic jumping that characterizes the female in heat. Evidently the young male does not readily differentiate these quick responses from the aggressive movements of attack, and therefore, responds in a manner appropriate to the avoidance of punishment rather than in a manner appropriate to effecting copulation. Fear responses of this type are seldom seen in the adult male, and they quickly disappear in the young after copulatory experience. In this connection it will be recalled that, according to Miller ('11), the female 
brown rat chased the young males about the cage and would not permit copulation, but when placed with large males she became quite submissive.

The sexual aggression of the young male is thwarted by slight resistance of the female more readily than is that of the adult male. Females which back-kick, and run wildly about the cages are less often subjugated by the young male. Likewise those that are extremely lethargic are less often forced into positions favorable for copulation. Although this is due, in part, to a difference in strength of the mature and immature male, it is due in greater part to a difference in aggressiveness. A change in this respect comes on rapidly after the act of coition has been initiated. Craig ('14) reports a similar change in the behavior of one of the doves.

Another kind of difference centers about the appearance of the elements of the copulatory act in a stage of slight disorganization. Illustrations of this are common in the copulatory attempts of the inexperienced male just prior to the first successful copulatory act. These elements may consist of mounting with or without definite clasp, mounting and palpation of the female's sides, and rarely, mounting and palpation of her sides with feeble pelvic movements that do not effect vaginal entrance. In the latter case further attempts to repeat the act are not made at once, contrary to the general rule in the case of the experienced male. The frequency of occurence of these partial attempts has been calculated for thirty young males from the records of their behavior with a female just prior to sexual experience. Sometimes the elements which appeared in dissociated or only partially integrated patterns anticipated the complete act by only a few minutes or an hour or two. In other cases they appeared several days earlier. These records show that of the thirty rats:

Six mounted with firm clasp, but with no other elements of the copulatory act involved, prior to the first complete act of coition.

Fourteen mounted and palpated the female's sides, but did not make pelvic movements.

Eight animals performed the complete act without previously performing any of the partial acts given above. 
The appearance of these dissociated elements is not confined to the young animal alone; it is sometimes seen in the adult as well. The difference is one of relative frequency only.

Following the first period of copulation the young animal is less discriminating in the mounting of other animals than the adult. He mounts without regard for sex or condition of receptivity. Here again the difference is largely one of degree characterized by persistence in mounting attempts, for the adults also have been observed to mount non-receptive females and males at various times after a period of copulation was brought to an end.

In two instances young males performed the first sexual act while mounted at the head end of the female and with the forelimbs clasping the head and shoulders rather than the sides. The pelvic movements were directed toward the face in these cases.

Licking the penis is, so far as observations in this study go, an invariable element of the complete copulatory act providing vaginal entrance has been effected. In the case of the young male the licking is oftimes omitted at the completion of the first sexual act. This probably, is due to incomplete erection and failure to make vaginal entrance.

b. The age of functional sexual maturity and the strength of the copulatory impulse. The age at which copulatory ability normally appears has never been determined under sufficiently controlled conditions to establish a reliable norm. Kirkham (13) reported that a pair of rats bred prior to the age of sixty days. Hewer ('14) considered rats of seventy days of age as sexually mature, for at that time she was able to find spermatazoa in the epididymis. My own observations show, however, that copulatory ability does not run exactly parallel to production of spermatazoa. Therefore, her criterion is not a reliable index of the age at which copulatory ability appears.

In table 12 are given data bearing on the age at which the first sexual act appeared in seventeen normal rats reared under conditions as nearly uniform as possible. The age and number of minutes given to testing each rat prior to the appearance of 


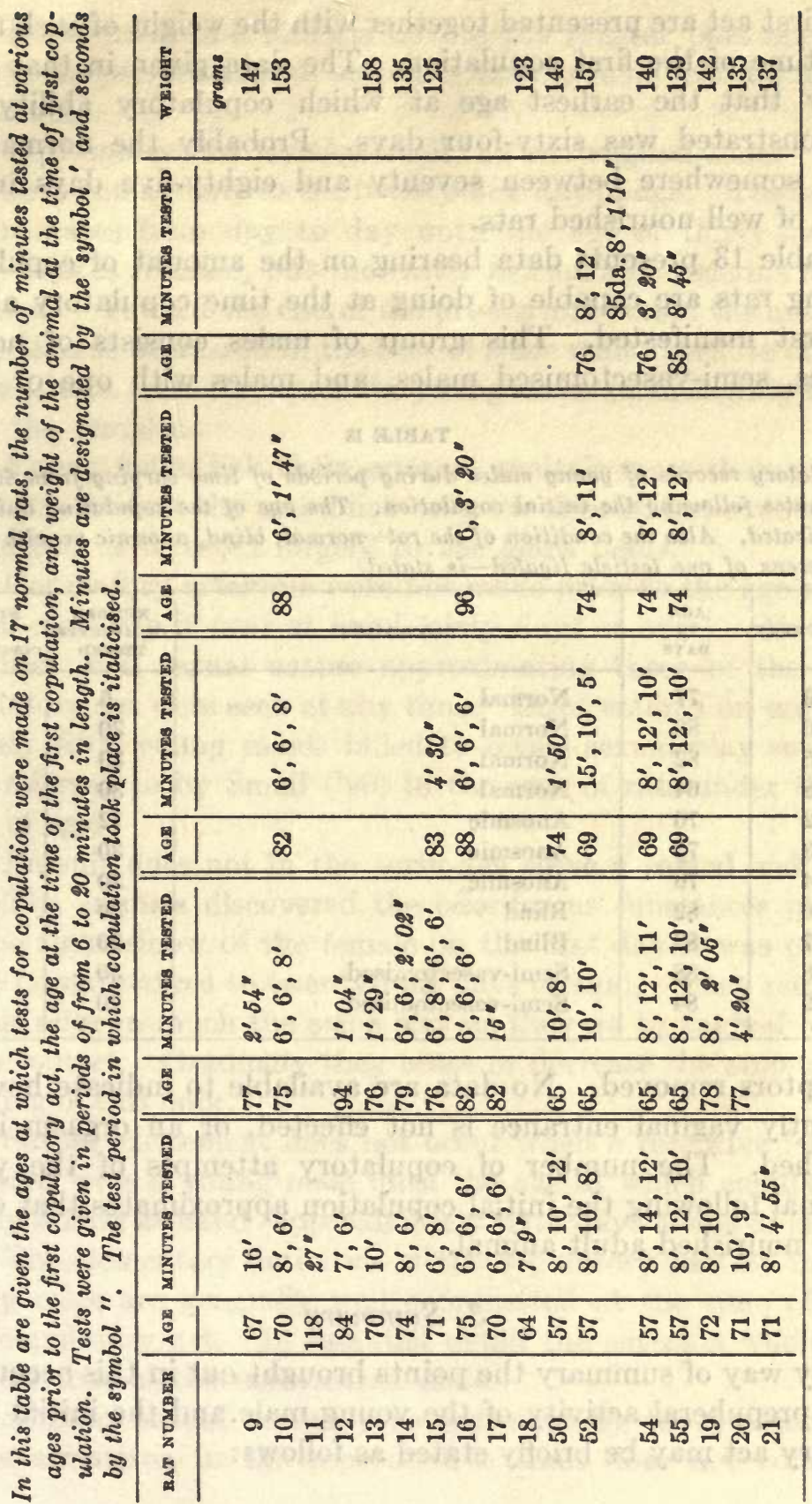


the first act are presented together with the weight of each rat at the time of the first copulation. The data given in that table show that the earliest age at which copulatory ability was demonstrated was sixty-four days. Probably the normal age falls somewhere between seventy and eighty-five days in the case of well nourished rats.

Table 13 presents data bearing on the amount of copulation young rats are capable of doing at the time copulatory ability is first manifested. This group of males consists of normal males, semi-vasectomised males, and males with one or more

TABLE 13

Copulatory records of young males during periods of time varying from 60 to 30 minutes following the initial copulation. The age of the copulating animal is indicated. Also the condition of the rat-normal, blind, anosmic or with ductus deferens of one testicle ligated-is stated.

\begin{tabular}{|c|c|c|c|c|}
\hline RAT NOMBER & $\begin{array}{l}\text { AGE } \\
\text { IN } \\
\text { DAYS }\end{array}$ & DEBCRIPTION & $\mid \begin{array}{c}\text { NUMBER } \\
\text { OF MINUTES } \\
\text { TESTED }\end{array}$ & $\begin{array}{c}\text { NUMBER } \\
\text { OF } \\
\text { COPULATIONS }\end{array}$ \\
\hline 9 & 77 & Normal & 6 & 13 \\
\hline 10 & 88 & Normal & 30 & 47 \\
\hline 15 & 82 & Normal & 30 & 31 \\
\hline 18 & 64 & Normal & 30 & 51 \\
\hline 22 & 76 & Anosmic & 12 & 8 \\
\hline 23 & 75 & Anosmic & 30 & 30 \\
\hline 24 & 76 & Anosmic & 30 & 30 \\
\hline 26 & 82 & Blind & 30 & 27 \\
\hline 27 & $82=$ & Blind & 20 & 53 \\
\hline 28 & 88 & Semi-vasectomised & 30 & 30 \\
\hline 29 & 84 & Semi-vasectomised & 20 & 27 \\
\hline
\end{tabular}

receptors removed. No data are available to indicate how frequently vaginal entrance is not effected, or an orgasm is not reached. The number of copulatory attempts of the young animal following the initial copulation approximates that of the well nourished adult animal.

\section{Summary}

By way of summary the points brought out in this account of the prepuberal activity of the young male and the initial copulatory act may be briefly stated as follows: 
1. Both males and females devote the greater part of their time to the performance of activities that have no relation to the sexual act.

2. Both males and females smell the ano-vaginal zone. This may be begun as early as the twenty-first day of age. The smelling increases from day to day until the age of thirty-five to forty days is reached, but thereafter the amount remains fairly constant. Toward the end of the pre-mature period the amount of smelling is decreased in the case of some males because of fear of the adults. On the whole the young males smell slightly more than the females.

3. Young males lick their external genitals more than young females. At first the males lick only the sheath, but eventually the licking is directed largely to the glans penis.

4. Copulatory attempts were not made prior to the age when sexual maturity is near at hand (sixty days or over). No play activities of a sexual nature approximating those of the true copulatory act were seen at any time. Observations on approximately fifty young males failed to reveal sexual play such as that referred to by Small ('99) in the case of rats under thirty days of age.

5. Pursuit does not in the early age serve a sexual end.

6. The animals discovered the odoriferous substances placed on the right elbow of the female on the first day it was placed there (twenty-three to twenty-four days of age). They respond to this odor in much the same way as they do to vaginal odors at the outset. Gradually they cease or decrease the amount of smelling of this odor.

7. Sexual excitement does not occur when a receptive female is placed with a young male until the age at which copulatory ability is near at hand (approximately sixty days of age or later).

8. The elementary activities of the copulatory pattern in the young male are generally well coördinated at the time of the first copulatory act. In essential detail the act as a whole resembles that of the experienced male.

9. Somatic sexual maturity as indicated by the presence of free spermatizoa in the reproductive tract does not coincide 
exactly with functional sexual maturity as determined by ability to copulate. The normal age at which copulatory ability is demonstrable is probably between seventy and eighty-five days. The variability, however, in animals reared under practically identical environmental conditions is great.

10. The young male is capable of copulating approximately as often during a period of thirty minutes following the initial copulation as an adult rat during a similar period of time. The largest number of copulations following the initial act recorded in this study is 51 in thirty minutes.

\section{STIMULATION LEADING TO COPULATORY RESPONSE}

The results of experimental observation indicate that complex congenital behavior is, like the reflexes, conditioned by an hereditary neural organization of receptors and effectors. This hereditary organization differs from that of the reflexes chiefly, if not wholly, in complexity of coördination. Hence it should be possible, because of this close kinship, to subject complex congenital responses to experimental control in a manner similar to that employed in the study of typical reflexes (Sherrington '06), and, by appropriate variation of technique, to analyse and define their adequate activating stimuli and the operation of the receptor-effector mechanism. In this way there would be brought together the kinds of data needed to give a complete account of the operation of complex patterns of congenital behavior in concrete, objective terminology.

The literature on congenital responses contains many statements concerning the rôle of external stimulation in the initiation of patterns of response. A statement from McDougal's "Social Psychology"2 illustrates the general typc. He says: "In the typical case some sense-impression, or combination of sense-impressions, excites some perfectly definite behavior, some movement or train of movements which is the same in all individuals of the species and on all similar occasions."

2 Sixth Edition, p. $25 \mathrm{ff}$. 
In a similar manner Havelock Ellis ${ }^{3}$ describes the arousal of sexual activities through particular kinds of exteroceptive stimulation. According to him:

External stimuli act at every stage, arousing or heightening the process of tumescence, and in normal human beings it may be said that the process is never completed without the aid of such stimuli, either active or in imagination.. . . . The chief stimuli which influence tumescence aud thus direct choice come chiefly-indeed, exclusively through the four senses of touch, smell, hearing, and sight. All the phenomena of sexual selection, so far as they are based externally, act through these four senses.

He evaluates the four senses with respect to their effectiveness in arousing sexual responses as follows: "Of the four sensestouch is the more primitive, and it may be said to be the most important, ${ }^{4}$ though it is usually the last to make its appeal felt. Smell, which occupies the chief place among many animals, ${ }^{4}$ is of comparatively less importance, though of considerable interest, in man; it is only less intimate and final than touch.",

Such statements, although lacking in concrete detail, are of interest in this connection because they serve to suggest a feasible point of attack for the study of the activation of the copulatory act. Given an inexperienced male rat which has reached the stage of physiological development denoting copulatory ability, one needs only to supply the adequate stimulusto evoke the copulatory act. Under this condition, a study of the process of activation consists primarily in the analysis and definition of the stimuli acting together with their mediation through the agency of the receptors.

Experiments along these lines, so far as they have been successful, indicate that with further extension of experimentation

Psychology of Sex, Vol.4, p. 1-2 incl.

Italics mine.

- Although these quotations are taken from his studies dealing primarily with the sexual life of man, they have in them points of general applicability to the sexual behavior of the lower animals as well, for the fundaments of his sexual theory as a whole are taken from data of comparative physiology and psychology. 
and refinement of technique the activation of the copulatory response can be described as completely as many of the well known reflexes have been described by the physiologists (Sherrington '06).

\section{Experimental control of exteroceptors}

From what is known of the functioning of receptors in the activation of well known reflexes (Sherrington '06) it may be inferred, for the purpose of setting up definite working hypotheses that their functions in the initiation of the copulatory act in the rat may be about as follows:

1. They may serve to locate other animals of the same species or animals capable of arousing sexual excitement in the male. As distance receptors they may set up seeking activities.

2. They may serve to differentiate the sexes.

3. They may have a selective sensitivity for certain kinds of stimuli arising from the female in heat. And by means of direct efferent connections with the ganglionic centers concerned with the reproductive mechanism may transmit the necessary impulses to arouse this mechanism to action.

4. They may serve to reinforce nervous processes underlying the sexual response, even though they have no direct reflex connections with the essential reproductive mechanism.

5. Or, by exciting glandular activities, they may cause secretions to be released into the blood stream which have the special function of sensitizing or giving tonus to the neuro-muscular mechanism involved in the act of copulation.

Each of the foregoing possible functions must be tested in the light of available experimental data to determine which if any of them are really involved in the initiation of the sexual act.

A. Vision. Very few references to the visual receptors in the literature on sex-studies indicate clearly the role of visual stimuli either as facilitators or excitors of sexual responses. Examples of the courtship of birds and other animals through display of special adornments or by movements of a particular kind are cited by Morgan ('00, p. $61 \mathrm{ff}$.) and others. In this case the 
visual stimuli were thought to be effectual in arousing the pairing impulse in the female bird. Andrews ('14) concludes that visual stimuli are unessential in the conjugation of the crayfish. Banta ('14) states that the wood frog is sexually excited at the mating season by objects moving within the radius of several feet. From this statement we infer that visual stimuli initiated the excitement. No previous investigations of the sexual function of the visual receptors in the rat have come to the author's attention.

a. Operative technique. The eyes of rats were removed under deep anaesthesia. A small piece of sterile cotton was immediately inserted into the orbits to absorb blood accumulating from transected branches of the opthalmic arteries. After all bleeding had ceased and the orbits were cleansed, the eyelids were brought together and overlaid by a small cotton-celloidin dressing. Case reports of the individual animals follow.

b. Experimental results. Rat 26. Eyes removed at age of thirty days. Tested at age of seventy days for copulation. No signs of sexual excitement and no attempts at copulation. Again tested at the age of seventy-seven days. Mounting and palpation of female's sides frequent. Made complete copulatory attempt once but apparently did not effect vaginal entrance. Tested at age of eighty-two days. Copulation appeared for first time. In a period of thirty minutes there were twenty-seven complete acts.

Rat 27. Eyes removed at age of thirty days. Tested for copulation at age of seventy-six days. Showed hyperexcitability but did not attempt to mount. Tested at seventy-seven days of age. No copulation. At eighty-two days the test was again given. Copulation appeared. Record for twenty minutes was forty-nine complete acts. A remarkable exhibition of potency was found in this animal. He copulated thirteen times during the first three minutes, and the same number of times during the second three minutes.

In the foregoing experiments with animals, normal in every way except that visual receptors were not present, no diminution in sexual excitement was observed in the young males prior to 
the initial copulatory act. Since they responded to the movements of the receptive females by pursuit and mounting, it is evident that visual stimuli were not necessary for the perception of these characteristic movements. The age at which copulation began is within the limits of variability for normal males (table 12, p. 127). The number of copulations of each animal during twenty or thirty minutes following the first act gives no indication of handicap either in potency or in ability to find the female in the cage (table 13, p. 128, rats 26 and 27). The copulatory record of no. 27 during twenty minutes exceeds that of any other animal tested in the laboratory. No experimental data is available to indicate to what degree vision is used in locating other animals of the same species or in differentiating animals of the same sex. In the above experiment neither of these functions was called for because of the condition of confinement during the observation. Casual observation of cage activities of rats of various sizes has led to the impression that rats from forty to fifty days of age have acquired habits of responding to the size of other animals without first coming into physical contact with them. If this impression is true, one might expect to find that the blind young males might be much less aggressive in their natural habitat if forced to compete in sexual activities with larger males because of the tendency of the larger to dominate the smaller. The dominating habits of the larger males might bring about an accentuation of the fear and defense response in the presence of other animals of either sex which would effectually shunt all congenital sexual responses.

$B$. Olfaction. It is generally believed that the sense of smell plays a very important part in the excitation of sexual response in various kinds of animals. This belief is founded upon the observation of males smelling the external genitals of females prior to copulation. In the case of the rat, vaginal smelling is a practice so common that different investigators have considered it an "excitant" to sexual activity. Thus Steinach (10) in discussing the arousal of the sexual impulse in rats assigned to the olfactory sense the function of setting the neural mechanism concerned with the copulatory act into activity after it has been 
made ready for action by the influence of internal secretions from the reproductive glands. He wrote as follows:

In bezug auf die Geschlechtsfunktionen kann man genau verfolgen, dasz sich die Wirkungen zunächst auf das Gehirn konzentrieren. Die Ganglien werden instand gesetzt, die vom Weibchen ausgehenden Sinneseindrücke (bie den Ratten sind es namentlich Geruchseindrücke) in Lustgefühle umzuwerten. Es entsteht das, was man heftigen Trieb sum Weibchen oder starke geschlechtliche Aufregung nennt.

In a similar tone von Bechtrew (211, vol. I, p. 395) writes of the rôle of smell: "Im engsten 'Lusammenhang mit den Geschlectsfunktionen steht der Geruchsinn, vor allem in der Tierwelt. Bei vielen Tieren spielt ferner der Geschlecksinn die Rolle eines mächtigen Erregers des Sexualtriebes."

a. Operative technique. A mid-sagittal incision was made in the scalp from points midway between the ears and the eyes. On either side of the incision the skin was retracted thus laying bare the skull. The skull plate was trephined lateral to the mid-line at sufficient distance to avoid rupture of the superior sagittal sinus beneath. With bone forceps a small triangular piece of bone, marked off by the trephine openings, was removed. This opening was just large enough to permit of the insertion of an instrument approximately one and one half millimeters wide. The removal of the small piece of skull plate left exposed the dura mater over the posterior part of the olfactory bulb and the anterior portion of the frontal lobe. Special care in cutting through the meninges was exercised in order to avoid rupture of the superior sagittal sinus. With this small operative field it is usually impossible to sever the olfactory bulb from the frontal pole without rupturing the anterior cerebral arteries as they swing around the frontal poles. The bulb was cut from the brain by introducing a small cautery into the opening of the skull and thrusting it downward to the base of the skull, thence moving it sufficiently both medialward and lateralward to effect complete transection of the bulb just anterior to the frontal lobe. Without removal the cautery was then so manipulated that the tip moved forward in the ethmoidal 
groove to the posterior wall of the frontal sinus. This served to destroy the filaments of the olfactory nerve which enter the bulb, coming from the nasal end-organs, through the cribiform plate, and provided a safeguard against functioning of olfactory system in the event that a small bundle of fibers of the tract was not transected. Time was allowed for coagulation of the blood coming from the ruptured arteries and veins; then all coagulated blood was removed by means of sterile cotton and the wound was closed. The cut edges of the integument and superficial fascia were brought together and sutured by interrupted stitches and a thin cotton celloidin dressing was applied to the region of the incision.

b. Experimental results. Rat 22. Operated at age of thirty days. Operation incomplete. Second operation age sixty-six days. Successful. Tested at age of seventy-six days. Copulated after eight minutes forty seconds exposure. Record for first twelve minutes was eight copulations. Record of copulations for thirty minutes at the age of eighty-one days was twentyone. Autopsy showed complete destruction of bulbs.

Rat 23. Operated at age of thirty days. Operation not successful. Operated at age of sixty-one days with complete abolition of smelling. Tested at age of seventy days for eight-minute period. At time for second period female was no longer receptive. No signs of sexual excitement in the first trial. Tested at the age of seventy-five days. Copulated at end of fifty-five seconds after female was placed in cage. Did not effect vaginal entrance. No further attempts in six minutes. In second period of six minutes no further copulations. At third period of exposure, copulation full and complete was renewed at fourteen minutes after female's return to the cage. Record for one half hour was thirty copulations. Autopsy showed complete destruction of bulbs.

Rat 24. Operated at age of thirty days. Incomplete destruction. Second operation at age of sixty-two days. Complete abolition of smelling. Tested at age of seventy-one days for periods of six minutes, eight minutes. No attempts at copulation, although there was frequent mounting without definite 
clasping and with no palpation. Probably not sexually excited. Tested at age of seventy-six days. No copulation in first period of eight minutes or second of six minutes, but copulation appeared in two seconds after female's entrance in the third period. Record for one half hour was thirty copulations. Autopsy showed complete destruction of bulbs.

Rat 25. Operated at age of thirty days. Operation did not destroy sense of smell. A few days after the operation smelling was renewed. Second operation at age of sixty days. Before the wound had entirely healed a slight scalp infection was noticed which infected the meninges at the point of operation and probably a part of the frontal pole. This caused arrest of growth for approximately two and one-half weeks. Recovery was very slow.

Tested for copulation at age of seventy-six days for periods of eight minutes, six minutes. No mounting or signs of excitement.

Tested at age of eighty-two days for periods of six minutes, five minutes, six minutes, six minutes. Placed fore feet on female's back and bit at her head short time, but was idle after three minutes. No mounting or signs of excitement during first two periods. During third period he jumped on female and clasped her firmly in true copulatory style, but did not palpate or pistonate. Tested at age of eighty-eight days for periods of six minutes, eight minutes, eight minutes. No excitement shown at any of the periods. Idle after first two minutes.

Tested at age of ninety-four days; periods eight minutes, eight minutes, eight minutes. (At this time the testes were small and flacid. The scrotum was pale.) No movements of a sexual nature during the first period. During the second and third repeated mounting and definite clasping without palpation were seen.

Tested at age of ninety-six days; periods eight minutes, eight minutes. During the first period male mounted and clasped several times but did not palpate. Female kicked him with her hind foot and made him wary of her for a short time. During the second period he mounted and palpated and once made the 
copulatory movements. Entrance to vagina not effected. Mounting repeated several times, but no further copulatory movement. Female non-receptive when third trial was begun.

Tested at one hundred and seven days. Copulated at four minutes, fifty-four seconds after female was placed in cage. Tried to copulate with female at end of fifteen seconds after her entrance to the cage, mounting with her head between his legs. Mounting and palpation frequent before the first copulatory movements were made. Female very resistant, therefore no record for thirty minutes was secured. Autopsy showed complete destruction of bulbs and considerable necrosis in frontal pole.

The foregoing experiments on the removal of the olfactory receptors show clearly that: (1) The sense of smell is not essential to the appearance of the sexual act in the inexperienced male; (2) That is has no direct connections with reflex mechanisms of the copulatory act, the abolition of which will entirely eliminate the act of coition; (3) That its excitatory function in the inexperienced male is doubtful, and, if really present under certain circumstances, is not essential to the initiation of the act; (4) That in its absence the appearance of the sexual act is neither retarded noticeably nor the potency of the young male modified, providing the operations do not result in complicating factors.

It seems probable that under normal conditions these receptors are used to some extent in differentiating the sexes, and in certain cases as distance receptors by which the location of the female is determined.

The erroneous nature of Steinach's view is clearly established by the results obtained with anosmic animals in this study. Likewise it has been shown that olfactory stimuli, although possible facilitators of the sexual instincts as von Bechtrew believes, are unessential activators and no perceptible modification of behavior follows their elimination. The conclusions with respect to smell are essentially in accord with von Bechtrew's statement as to the importance of the olfactory stimuli for the arousal of the sexual instincts of the dog, except that it lends no support to the view that smell has an excitatory function. With 
respect to olfactory stimuli and the sexual instinct of the dog, he says:

Ebensowenig bewirkt die Zweiseitige Abragung der Lobi Olfactori des Hundes eine Störung der Geschlechtsfunktionen. Die so operierten Tiere wiesen analogie Verhältnisse der Libido sexualis auf, wie gesunde Tiere; der einzige Unterschied zwischen ihnen bestand darin, dasz sie, des Geruchssinnes beraubt, nicht selten ihren Geschlechtstrieb nicht nur Während der Laufzeit, sondern auch auszerhalb derselben zu befriedigen suchten.

Man möge hieraus abnehmen, dasz die von einigen Autoren vertretene Ansicht, der Geruchssinn spiele die Hauptrolle der Geschlechtsfunktion, nicht ohne weitererichtig ist.

Dasz der Geruchssinn die Bedeutung eines richtigen Hilfsfaktors für die Erregung des Geschlechtstriebes bei einigen Tieren spielt, ist zutreffend, aber auch nicht mehr, denn auch nach dem Verlust des Geruches befriedigen diese Tiere noch ihnen Geschlechtstrieb. [von Bechtrew ('11) p. 1696.]

C. Vision and olfaction. Since no noticeable effect on the appearance of the act of copulation in the young animal resulting from the loss of sight or smell was found, it was thought advisable to test the effect of removal of the two senses in a single individual before the act had been initiated. The results of this experiment follow:

Rat 30. Operated at the age of thirty days to render anosmic. First operation successful. No attempts at smelling later at any time. Kept in isolation until seventy days of age, then eyes removed and vibrissae cut short. Placed with two others in similar condition for short periods daily, after seventy-third day and until the seventy-seventh day, to accustom him to the contact of other animals in the cage. Tested at age of seventyeight days for periods of ten minutes and fifteen minutes but no excitement was shown. Copulated at age of eighty-two days after a period of exposure of six minutes. Copulated during the subsequent five minutes as frequently as normal animals. Autopsy showed complete destruction of olfactory bulbs.

Rat 31. Operated at the age of thirty days to render anosmic. Operation successful. Conditions of confinement same as those 
of Rat 65. Eyes removed at age of sixty-eight days. Tested age of seventy-six days for copulation for periods of twelve minutes and sixteen minutes but no attempts at mounting were made. Tested at age of eighty days. Copulation followed the introduction of the female into the cage in forty-five seconds. Frequency of the act normal. Autopsy showed complete destruction of olfactory bulbs.

Rat 32. Operated at the age of thirty days to render anosmic. Operation successful. Conditions of confinement same as those of the other two above. Eyes and vibrissae removed at age of sixty-eight days. Tested for copulation at age of seventy-six days for periods of twelve minutes and sixteen minutes with no signs of sexual excitement. Tested at age of eighty days. Copulated four and one-half minutes after female was placed into the cage. Autopsy showed complete destruction of olfactory bulbs.

The anosmic rats in which the act of copulation was initiated in the absence of smell only were subjected at a later time to other observations following the removal of their eyes. The results of these tests follow:

Rat 23. (Anosmic and sexually experienced in copulation.) First copulation at age of seventy-five days. Operated at age of eighty-one days to remove eyes. Tested for copulation at age of eighty-eight days, seven days after eyes were removed. Copulated four seconds after female was placed in cage. Record for one half hour was thirty-seven copulations.

Rat 24. (Anosmic and sexually experienced in copulation.) On seventy-sixth day of age copulated for period of thirty minutes. Eyes removed at age of eighty-one days. Tested at age of eighty-two days, one day after eyes removed. Copulated seven seconds after female entered cage. Record for one half hour was twenty-nine acts.

D. Vision, olfaction and taste. The taste receptors were effectively controlled and eliminated as factors in the initiation of the copulatory response without destruction of the special end organs. The anosmic animals observed ceased all vaginal exploration when brought into the company of the female after the olfactory bulbs were destroyed. Young anosmic animals 
tested for copulation began the act without any licking of the female either in the vaginal or other regions of the body. Hence it is clear that taste played no part in the arousal of the copulatory response.

E. Vision, olfaction, taste, and vibrissae. Rats $30,31,32$ when both blind and anosmic were, in addition, without vibrissae. From the age of approximately fifty days the vibrissae were kept cut close to the skin. Both copulated as the records given heretofore indicate without signs of handicap from the loss of vibrissae.

F. Audition. Less is known concerning the function of audition in the initiation of sexual behavior than concerning the other primary senses. Many examples of the use of vocalizations in the courtship of birds are given by Darwin ('01), but in these cases, it appears that the calls were made by the male for the purpose of arousing the pairing impulse in the female. The mating calls of many of the larger mammals during the rutting season are well known, but these calls are means of locating others of their kind, particularly of the other sex. Craig ('14) reports that doves employ vocalizations in the preliminary courting behavior. One male, however, was observed which omitted the calls entirely for a long period of time. Some observations on the sex behavior of the Poitu jacks reported by Pearl ('13) from the Breeder's Gazette indicate that auditory stimuli may become effectual in arousing sexual excitement. Such devices as "sing-song" whistling, and klicking of the latch were successfully employed by the keepers. In this case, the response described is without doubt a result of habit formation. Havelock Ellis (foregoing quotation, p. $44 \mathrm{ff}$.) is inclined to regard the auditory sense as the least important of the four primary senses for the arousal of sexual desires in man.

In the case of the rat it is probable from observations at hand that under certain conditions (rats blind and anosmic) the male receives auditory cues from the movement of the female about the cage which serve to guide him in his approach to her. Such sounds as the female makes in her cage movements are not of such distinctive character, however, as would permit of differen- 
tiating the sexes or discriminating between the receptive and the non-receptive female. Since the female makes no vocalizations characteristic of the oestral cycle it may be assumed, therefore, that these stimuli play no direct part in the arousal of sexual activity in the young male. Experimental results on the control of audition will be given although the data is less conclusive for this sense than for the senses just discussed.

With rats 23 and 24, which were at this time blind, anosmic and without vibrissae, and had previously been observed to copulate, an attempt was made to prevent audition by destruction of the tympanic membrane of the middle ear and filling the tympanic cavity and the external auditory meatus with melted paraffin. Control tests showed that the animals could hear and localize sounds. Next an attempt was made to destroy the cochlear ganglion by the injection of absolute alcohol into the cochlea. Control tests showed that the ability to localize sounds was greatly impaired, but that there still remained some ability to respond to auditory stimuli. Diffusion of the alcohol along the trunk of the auditory nerve affected not only the auditory sense but also the vestibular apparatus with the result that undesirable interference with the equilibratory mechanism was produced. This complication made it necessary to abandon the method and the problem was dropped temporarily until satisfactory technique for the unequivocal control of the auditory receptor could be worked out.

When tested for copulation, both rats 23 and 24 continued to copulate following the partial destruction of the auditory sense organ, although the equilibratory mechanism was greatly disturbed.

G. Cutaneous and deep sensibility. Cutaneous and deep sensibility appear to be the most fundamental senses involved in the arousal of the copulatory response. It is probably the medium through which afferent impulses are aroused which cause the definite mounting clasp, erection of the penis pelvic movements whereby the penis is brought into contact with the walls of the vagina, and the other constituent elements of the copulatory response. Ejaculation, likewise is probably brought 
about by tactual and thermal stimulation of the penis within the walls of the vagina. Just how these stimuli produce their effects is a problem for future analysis.

Cutaneous and deep sensibility have not been subjected to experimental control in this study. Technical difficulties encountered in the control of their individual receptors are exceedingly great and may prove to be unsurmountable because of their inaccessability and the diffuse distribution throughout the body. The use of drugs for the dissociation of sensibility for particular regions of the body is unsatisfactory because of the difficulty of controlling and limiting the range of drug influence on neighboring tissues. Nerve section followed by gross dissection and histological examination at autopsy to determine the range of distribution of destroyed nerves may be a feasible method of dissociating the cutaneous from the deep sensibility, but this method of approach will involve refinement of technique beyond that now available.

Further definition of the adequate stimulus has been attained through observation of the behavior of young males and adult females at the time of the initial copulation of the former. This has also been accomplished by the use of artificial patterns of stimulation to evoke the sexual act.

\section{Artificial reproduction of pattern of stimulation}

While young males were being tested to determine the earliest age at which copulatory ability appears it was discovered that the amount of sexual excitement aroused in the young male depended to a marked degree on the excitability and responsiveness of the receptive female. Females that were very sensitive and move quickly upon being touched by the young male were, invariably, most effective in arousing sexual aggression on the part of the male. On the other hand, those that were unresponsive to the light tactual stimuli of the male, sniffing and nosing the ano-vaginal zone, but responded only to vigorous treatment, such as the more aggressive adults were accustomed to administer, seldom aroused strong and prolonged sexual excitement in the inexperienced male. This observation is true for adult males, 
as well, which are not aggressive or are on the verge of sexual impotency. On several occasions aggressive adult males were seen copulating repeatedly with lethargic females, whereas other potent but less aggressive adults made no attempts whatever.

Practical application of the foregoing discovery was made in an endeavor to provide artificially a movement-stimulus which would serve as an inducement for the young to attempt copulation with a non-receptive rat from which none of the odors characteristic of the female in heat emanated. In this way it seemed probable that some evaluation of the importance of the movement-stimulus could be made in the absence of the olfactory stimulus.

A female, having been tested and found unreceptive, was made extremely sensitive to touch in the vaginal region by painting the root of the tail and the ano-vaginal zone with a very weak solution of hydrochloric acid. She was then placed with a vigorous young male seventy-eight days of age which had not had previous experience in copulation. In a short time the male began nosing and licking in the vaginal region. The female responded to these tactile stimuli applied in the hypersensitive vaginal zone by jumping away from him. Signs of sexual excitement with a tendency to follow appeared at once in the male. This mild excitement and sexual aggression was continued for a few minutes with no accentuation until finally the female upon being touched darted forward suddenly in the cage away from the male. He pursued instantly and, overtaking her with a few bounds, performed the complete copulatory act insofar as this was possible without the coöperative action of the female. He repeated the act again and again before the female was removed from the cage. Similar responses were obtained with another young male by modifying, in a similar manner, the behavior of a non-receptive female so that it resembled the characteristic behavior of the receptive female.

In another instance, a young female guinea-pig, whose size approximated that of an adult rat, was placed into the cage of an inexperienced male seventy-four days of age. This rat had been reared in isolation from the age of thirty-five days. Although he 
had never before been with an animal other than his kind, he approached the guinea-pig without fear. The latter was moderately tame, but ran from the rat when he touched her while nosing about. In a short time he began smelling and nosing in the vaginal region whereupon the young guinea-pig ran away; but the young male did not pursue at this time. They were left together in the cage for one hour with no signs of sexual excitement on the part of the male. Three hours later, the same guinea-pig was returned to the cage of the rat. As in the previous instance, the latter soon began nibbling and smelling and as before, she darted away when he touched the sensitive regions about the vagina. Gradually after numerous repetitions of the smelling and the female's running away the male began to manifest signs of sexual excitement. Eventually he pursued and attempted to mount her as she darted forward. Mounting attempts more vigorous and persistent followed, and before the period of observation ended he was seen on several occasions in hot pursuit of the guinea-pig with his fore-paws clasping her sides and leaping along behind her on his hind feet as she darted about the cage. Subsequent trials resulted in a repetition of the foregoing behavior. Copulation was not observed.

To summarize the foregoing preliminary experiments it may be said that the following objects are adequate to evoke the copulatory act in an inexperienced male which has reached the proper state of physiological development: an active female in heat, and a female not in heat which has been made to respond to his exploratory activity by quick movements resembling those of a female in heat. Sexual excitement was aroused followed by partial attempts at copulation by a small guinea-pig which moves about the cage in a manner somewhat resembling that of the female in heat.

\section{GENERAL REMARKS}

The scope of this study is limited to an account of the copulatory pattern and its activation. Data bearing on the internal factors which condition the response will be presented in a subsequent paper. In its present stage of completion this investi- 
gation leaves many unsolved problems for future consideration, but, nevertheless, it demonstrates clearly the fruitfulness of the experimental method of approach. Certain data considered briefly in the foregoing pages are of sufficient importance because of their bearing on the general subject of congenital behavior to justify greater emphasis than heretofore given.

\section{Three fundamental aspects of congenital behavior}

From the standpoint of objective psychology, the chief lines of interest in unmodified congenital behavior center in three fundamental aspects of its nature and operation. These lines of interest call for studies of particular patterns of congenital behavior for the purpose of analyzing: (1) The constituent elements and their temporal, serial, and functional relationships; (2) The kinds of stimuli adequate to evoke the unit of response under observation and the manner in which they activate the effectors through the medium of the receptors and the nervous system; and (3) The internal factors operating within the organism to $(a)$ provide the special structures, if any, involved in the response, $(b)$ to integrate these and other structures into mechanisms for coördinated action, and $(c)$ to sensitize the receptor-effector mechanism for response of a definite pattern to stimuli of a special character.

Having analyzed each of these aspects, the experimenter will then be prepared to give not only a detailed account of the initial appearance of the pattern of behavior studied, but also will have acquired the factual background needed to facilitate an examination of the modification it undergoes during a life of exercise in an ever changing environment. Thus can be brought together a valuable fund of scientific information which will be of service to students of psychology and closely related sciences who are concerned with the application of all available facts in the field of native behavior.

\section{The copulatory act an hereditary mechanism}

The results of this investigation substantiate the generally accepted view that the copulatory response is the action of an 
hereditary mechanism. No evidence was found supporting the view expressed in a recent paper (Kuo '21), in which, if my interpretation of the article is correct, the author denies the hereditary organization of such mechanisms. He regards them as products of experience. A careful consideration of the experimental data on this subject indicates quite clearly, it seems, that this latter view is not in harmony with the existing facts.

\section{Precision in the initial copulatory act}

The copulatory act differs quite strikingly from many of the early post-natal responses with respect to the precision of functioning of its elementary components. Greater precision is to be expected, however, because of the more advanced stage of physiological development reached by the animal prior to the first copulatory act. The slight irregularities described in a foregoing section of the paper may be variously explained. In some instances they are probably the result of physiological immaturity of some of the structures involved; in others, due to incomplete integration of the elementary activities of the copulatory unit or to incomplete dissolution of these elements from other distinctly foreign units with which they have functioned previously; or, again, they may arise from the failure of neural arcs of the copulatory act to gain priority over other arcs aroused by stimuli acting simultaneously with the stimulus adequate to evoke the copulatory act. ${ }^{-}$The vigor of the copulatory mechanism in the young male, as measured by the number of complete copulatory attempts made in a given time interval, closely approximates that of the experienced adult. This, however, cannot be taken as a measure of relative precision in the delivery of the spermatazoa and their fluid media to their proper receptacle in the reproductive tract of the female. Data which indicate the rate and range of improvement in this function are not available. 4. Native and modified native elements comprise the copulatory act Inspection of the constituent activities of the copulatory pattern reveals a point ${ }^{7}$ that has oftimes been described in the lit-

- Sherrington, C. S., The Integrative Action of the Nervous System, p. 231.

' See especially Morgan, C. Lloyd: Animal Behavior, 1901. 
erature on delayed responses. The act is a compound of both native and modified native or acquired responses. The latter have been exercised in connection with other units of response and habitual performances from the time of their initial appearance to the time of their incorporation in the copulatory pattern. It is important to note, however that these elementary acts exercised in prepuberal life were not substitutes for or abbreviated and playful types of the copulatory act. The evidence does not show that their early exercise was, in some mysterious manner, pointed toward acts of greater precision in the reproductive function. Such activities as pursuit of other rats, playful clasping, wrestling, vaginal smelling, and nibbling have no demonstrable connection with the copulatory act prior to their incorporation in this act at or near the age of physiological sexual maturity. The function of penis licking is still a matter of conjecture. Though it may sometimes be shown to be a form of masturbation or in other respects connected with the process of tumescence or detumescence, there is no evidence at the present time which links it with the activation of the copulatory act. Palpation of the female's sides, piston movements of the pelvis, and the backward lunge characteristic of the copulatory act are activities which have never been observed prior to the first real copulatory attempts.

The evidence from this study harmonises, on the whole, with the view that the elements of the copulatory act are integrated into a functional unit of response at a rather definite period of the rat's life. Prior to this integration they do not function in isolation or in smaller units of action which are the anlage of the copulatory act. This point is of special interest because of its bearing on the sexual theories of infancy promulgated chiefly by the Freudian School. Because of the relation such facts have to this interesting subject, it is desirable to extend the present osbservations to other animals and to the human infant as well to determine to what degree these findings are common. In this way data will be made accessable to test the correctness and appraise the value of these theories. 


\section{The adequate activating stimuli}

Analysis of the activation of the copulatory act is not sufficiently advanced, as yet, to enable one to define accurately the stimuli adequate to evoke the copulatory response on the first occasion of its appearance. It may be said, however, on the basis of available data, that the adequate stimuli are probably both mechanical and thermal in nature, and that they are almost certainly mediated through the cutaneous receptors and the receptors of deep sensibility. In some way the movements of the female ordinarily supply the stimuli which under the proper conditions initiate the act. The effectiveness of these stimuli is assured, as will be shown later, only after certain internal factors have done their work toward preparing the receptor effector mechanism for response to this particular pattern of stimulation.

\section{Fundamental need of more experimental data on congenital} behavior

Heretofore no special comment as to the bearing this study has on the current discussions of "instinct" has been given. The use of this term is unnecessary in the exposition of experimental data; furthermore, its use is undesirable in this connection because of the difficulty in so defining the term as to disentangle it from its many obsolete and unscientific attachments.

It must be obvious to all who have reviewed recent discussions of the term "instinct" that the chief cause of our inability to elucidate the field of congenital activity cannot be attributed primarily, or even in large measure, to the general abuse of the term, "instinct," or any of its equivalents. Neither is it due primarily to faulty interpretations of the past or deprivation of plausible interpretations just recently brought forward. The cause is far more fundamental. The difficulties cannot be obviated by discussion alone. They must be overcome through experimentation. The paramount need at the present time is a broader factual acquaintance with the detailed nature and operation of congenital behavior mechanisms. It 
is a need which must be met by carefully planned and executed studies of native behavior designed to give facts making possible a complete account of patterns of congenital behavior, their activation, their internal conditioning factors, and finally their modifications through exercise. Results of this kind should be a reliable guide in determining what classificatory terms must be discarded, re-defined, shorn of their unscientific encumberances, or enriched by further interpretation.

\section{CONCLUSIONS}

The data herein presented seem to justify the following conclusions:

1. On the whole the evidence brought forward indicates that the chief elements of the primary reproductive act appear within a short period of time at the age of puberty. Activities such as smelling the vagina, pursuit and playful clasping seen in wrestling have no definite connection with the copulatory act prior to the age of sexual maturity. At that time the function of smell in the initiation of the act is wholly negligible. Licking the penis appears in prepubertal life at about the forty-fifth day and probably serves the same function thereafter when acting in isolation as when it is incorporated in the copulatory pattern. Palpation of the female's sides, pelvic movements, and the backward lunge are elements of the act which have no exercise in prepubertal life.

2. The overt pattern of the sexual act consists of the following elements: (a) Pursuit and mountings; (b) palpation of female's sides. (c) depression of lumber region of back, on the part of the female, with the consequent elevation of the sacro-coccygeal region; (d) pelvic movements of the male by which the penis is thrust in piston-like action toward the vagina; (e) cessation of palpation of female's sides and the backward lunge; $(f)$ licking the penis.

3. Differences between the initial copulatory act and the act as modified by age and experience are found. Minor differences, due to purely physical limitations of size and strength, are found in the location of the fore-paws on the female's sides, vigor of 
palpation of female's sides, and reduction of force of backward lunge. More important differences are: Increase of aggressiveness with sexual experience; incomplete patterns of the act involving omission of the essential elements such as palpation, pelvic movements and backward lunge; failure to lick the penis after copulation; and mounting in a manner that will not permit the completion of the full copulatory act, i.e., mounting at head.

4. The age at which the initial copulatory act appears is related to general physical development. The earliest age at which the act was initiated in this study was sixty-four days. It does not appear prior to somatic maturity. On the other hand, somatic maturity is not a reliable indication of copulatory ability.

5. The number of copulations following the initial experience compares favorably with that of adult males. The usual number during thirty minutes subsequent to the first act is from twenty-five to thirty-five. The greatest number observed in this study was 53 during the first twenty minutes.

6. The movements of a receptive female appear to supply the adequate stimuli for the initiation of the copulatory act. Movements of adult rats that simulated those of a female in heat brought out sexual acts, complete in pattern from the male's standpoint, in the case of two males that had not had sexual experience. The quick movements of a guinea pig served to arouse great sexual excitement in a young male. Excitement was accompanied by mounting attempts, but no complete acts.

7. Sensory controls reveal the following:

a. Visual stimuli are not essential to the initiation of the copulatory act. No visible effects in their absence are seen in the nature of the pattern, the pursuit tendency in mounting, the age of first copulation, or the rate at which copulations may take place.

b. Olfactory stimuli are not necessary for the arousal of sexual excitement or the initiation of the copulatory act. Their absence neither retards the age at which the act first appears, or modifies the sexual drive as manifested by eagerness to copulate and ability to copulate for a prolonged period of time. 
c. Elimination of visual, olfactory, gustatory sense organs and the vibrissae prior to sexual experience produces no changes in the sexual act, either in the pattern, the age at which it appears, or the responsiveness to stimulation of a female in heat. Substitute action of the visual, olfactory, or gustatory senses is, therefore, improbable.

d. Partial elimination of auditory sensitivity in blind and anosmic rats after sexual experience makes no change in the ease or arousing the pairing impulse. Experiments of this evidence that audition is an essential receptor for the initiation of the copulatory act in the rat.

$\boldsymbol{e}$. The lack of evidence for any important function of each of the other primary senses in the initiation of the copulatory act points to cutaneous and receptors of deep sensibility as the primary organs that mediates the exteroceptive stimuli by which the act is initiated.

\section{REFERENCES}

ANDREws, E. A.: Conjugation in the crayfish. Jour. Exp. Zool., 1914, 9, 235-265. Banta, Arthur M.: Sex recognition and the mating of the wood frog. Biol. Bull., 1914, 26, 171-184.

voN BeCrtrew, W.: Die Funktionen der Nervencentra. 1908, 3, 1.

Craig, Wallace: Behavior of young birds breaking out of the egg. Jour. of Animal Behav., 1913, 2, 296.

Craig, Warlace: Male doves reared in isolation. Jour. of Animal Behav., 1914, 4, 121-133.

Darwin, Charles: Descent of Man. Popular Edition. London, 1901.

Ellis, Havelock: Studies in the Psychology of Sex, 3, 4.

Groos, KArL: The Play of Animals. 1898.

Hamilton, G. V.: A study of sexual tendencies in monkeys and baboons. Jour. of Animal Behav., 1914, 4, 295-318.

HEWER, EveLYN E.: The effect of thymus feeding on the activity of the reproductive organs in the rat. Jour. of Physiol., 47, 479-490.

KIRKнам, WM. B.: The breeding habits, maturation of eggs and ovulation of the albino rat. Amer. Jour. of Anat., 1913, 15, 291-317.

KUo, ZING YANG: Giving up instincts in psychology. Jour. of Philosophy, 1921, 18 , no. 24,645 .

McDovgar, Wm.: An Introduction to Social Psychology. Sixth Ed. 1912.

MrLler, Newton: Reproduction in the brown rat. Amer. Natural., 1911, 45, $623-635$.

Montane, Lours: A Cuban Chimpanzee. Jour. of Animal Behav., 1916, 6, 330-333.

Sherrington, C. S.: The Integrative Action of the Nervous System, 1906. 
Small, W. S.: Notes on the psychic development of the white rat. Amer. Jour. of Psychol., 1899, 2.

Steinach, E.: Untersuchungen zur Vergleichenden Physiologie der Mănnlichen Geschlechtsorgans. Pflüger's Archiv., 1894, 56.

Steinacr, E.: Geschlectstrieb und echt sekundäre Geschlechtsmerkmale als: Folge der inneresekretorischen Funktion der Keimdrüsen. Zentralbl. f. Physiolog., 1910, Bd. 24.

SterNacH, E.: Willkürliche Umandlung von Säugetiermännchen in Tiere mit ausgeprägt weiblichen Geschlechtscharakteren der Keim drüsen. Archiv. f. d. ges. Physiol., 1912, Bd. 144.

Strinach, E.: Feminierung von Männchen und Maskulierung von Weibchen. Zentralbl. f. Physiol., 1913, 27, 717-723. 


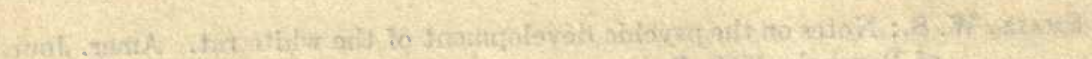

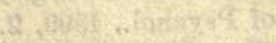

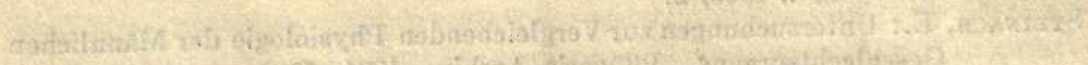

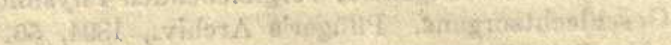

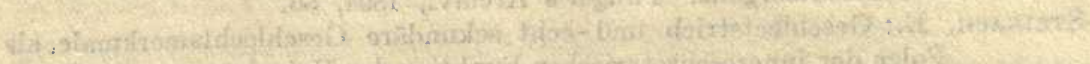

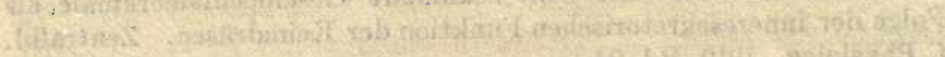

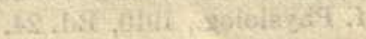

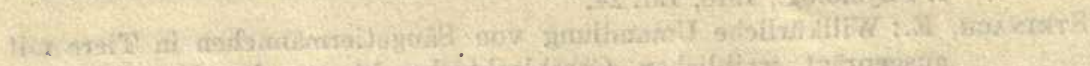

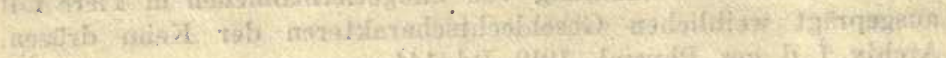

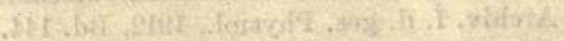

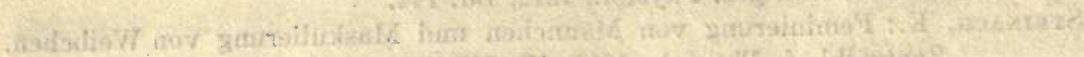

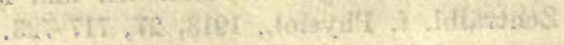



THIS BOOK IS DUE ON THE LAST DATE STAMPED BELOW

AN INITIAL FINE OF 25 CENTS WILL BE ASSESSED FOR FAILURE TO RETURN THIS BOOK ON THE DATE DUE. THE PENALTY WILL INCREASE TO 50 CENTS ON THE FOURTH DAY AND TO \$1.00 ON THE SEVENTH DAY OVERDUE.

\begin{tabular}{|c|c|}
\hline BIOLOGY & LIBRARY \\
\hline ग्याi $8 \quad 1938$ & \\
\hline IIUN \& 1939 & \\
\hline DEC $6 \quad 1939$ & \\
\hline AER 1 is & \\
\hline OCT 291961 & \\
\hline CजT 291901 & \\
\hline NOV 121961 & \\
\hline 23 J.ण2द & \\
\hline & \\
\hline & \\
\hline & \\
\hline & \\
\hline & LD 21-5m-7, 37 \\
\hline
\end{tabular}




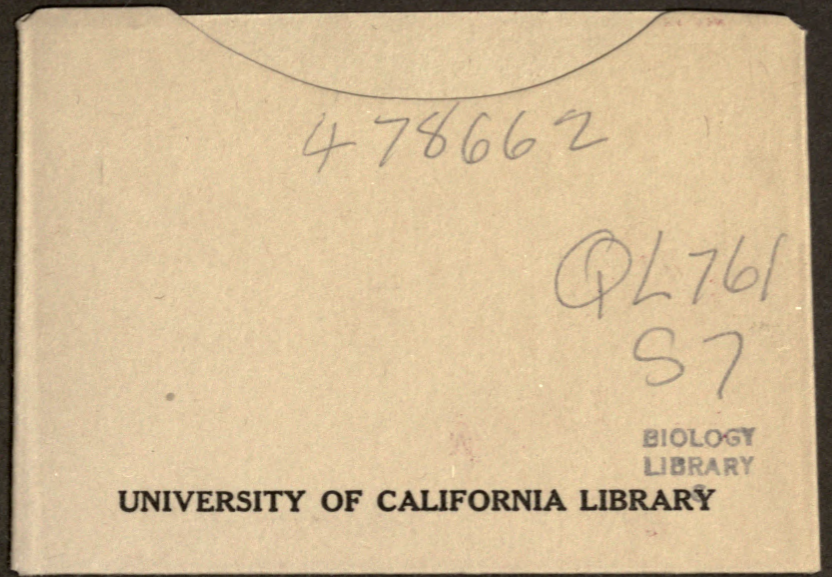




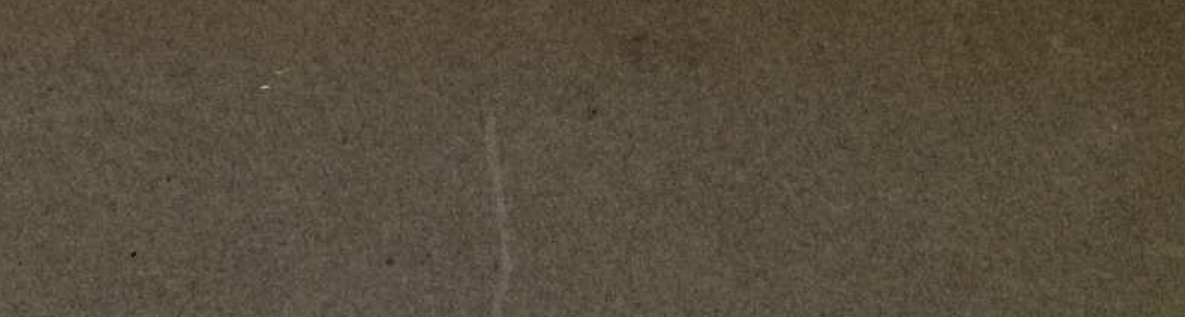

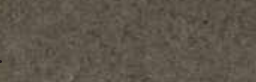

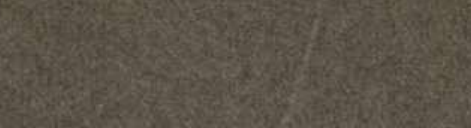

(2)

20.

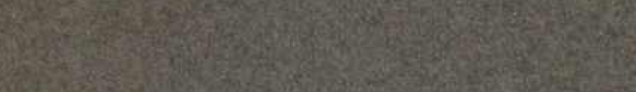

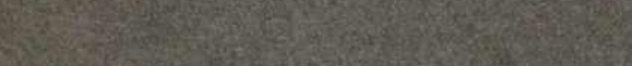

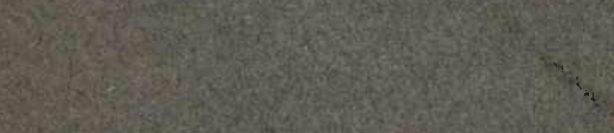

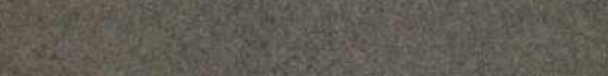

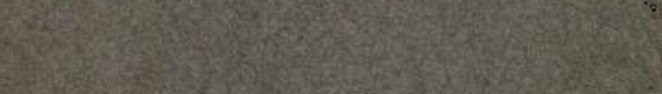

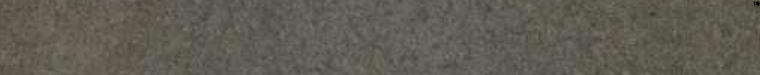

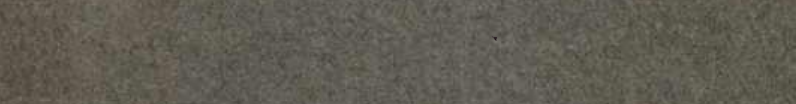

(2)

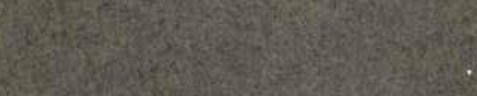

53.

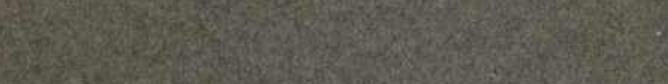

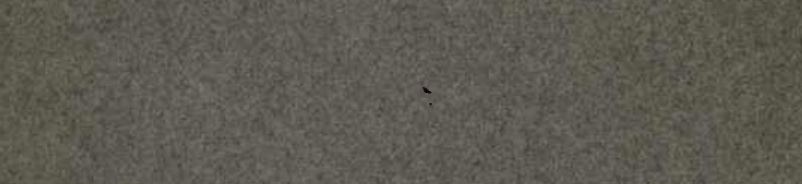

(2)

W.

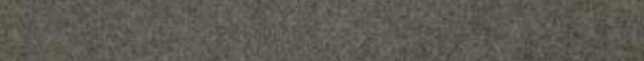

We.

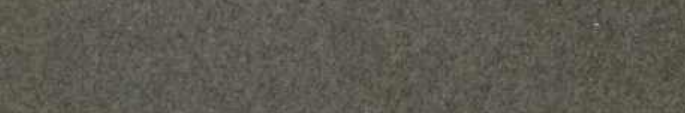

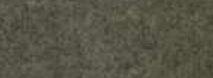
40.

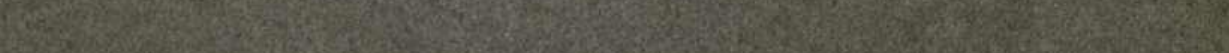

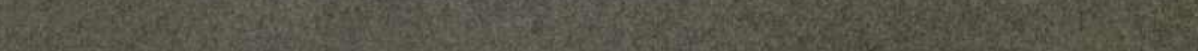

